\title{
Inter- and Intra-generational Consequences of Pension Buffer Policy under Demographic, Financial and Economic Shocks
}

\author{
Alessandro Bucciol \\ Roel M. W. J. Beetsma
}

CESIFO WORKING PAPER NO. 2779

CATEGORY 3: SOCIAL PROTECTION

SEPTEMBER 2009

Presented At CESifo Venice Summer Institute, July 2009

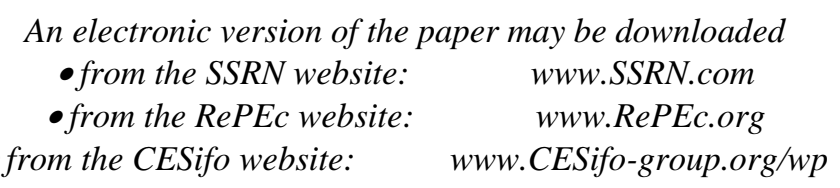




\title{
Inter- and Intra-generational Consequences of Pension Buffer Policy under Demographic, Financial and Economic Shocks
}

\begin{abstract}
We study numerically the inter- and intra-generational welfare consequences of alternative pension fund policies in response to unexpected demographic, financial and macro-economic shocks. Our analysis is based on an applied many-generation OLG model describing a smallopen economy with heterogeneous agents featuring a two-pillar pension system (with PAYG and funded tiers). We explore two policies to avoid underfunding of the pension funds. One is to always first raise the pension contribution rate ("contribution policy"), the other is to always first reduce indexation to productivity and price inflation ("indexation policy"). These policies have different consequences for different generations. Of the existing generations, on average the youngest prefer the indexation policy, while the older generations prefer the contribution policy. When expressed in terms of a constant difference in rest-of-life consumption the consequences of switching from one to the other policy are generally non-negligible. They also differ rather widely for the various cohort/income groups. Our stochastic simulations show that pension buffers are highly volatile when the shocks are drawn from realistically modelled multivariate shock processes. Underfunding occurs relatively frequently. Most of the volatility arises from uncertainty about the yield curve (the rate at which pension liabilities are discounted).
\end{abstract}

JEL Code: H55, I38, C61.

Keywords: funded social security, pension fund policy, shocks, funding ratio, stochastic simulations.

\author{
Alessandro Bucciol \\ University of Amsterdam \\ Department of General Economics \\ Roetersstraat 11 \\ The Netherlands - 1018 WB Amsterdam \\ a.bucciol@uva.nl
}

\author{
Roel M. W. J. Beetsma \\ University of Amsterdam \\ Department of General Economics \\ Roetersstraat 11 \\ The Netherlands - 1018 WB Amsterdam \\ r.m.w.j.beetsma@uva.nl
}

This version: August 27, 2009

The authors thank Lans Bovenberg, Frank Caliendo, Wouter den Haan, Olaf Sleijpen, Ward Romp, Siert-Jan Vos and participants at meetings of Mn Services and Netspar and at the CESifo Venice Summer Institute 2009 for useful comments. Financial support from Netspar and Mn Services is gratefully acknowledged. The usual disclaimers apply. 


\section{Introduction}

All around the world interest in funded social security is increasing. However, the properties and welfare consequences of funded social security systems are still insufficiently explored. In particular, such systems are relatively heavily affected by exogenous shocks (Sita and Shoven, 2003; Diamond, 2004), which raises discussions about risk sharing among generations (see Gollier, 2008). In this respect, the social security system in the Netherlands represents an ideal framework to study.

Dutch social security is characterised by a three-pillar pension system: a pay-as-you-go (PAYG) defined-benefit first pillar for which every inhabitant is eligible, a funded defined-benefit second pillar that is mandatory for most employees, and a voluntary funded third pillar. The first pillar allows for intra-generational redistribution, because contributions are wage dependent, while benefits are flat. The second pillar is formed by pension funds that receive contributions from workers and firms, invest those contributions and pay benefits to the retired. Through their contributions workers accumulate within a personal account claims to nominal benefits once they are retired. The Dutch system somewhat resembles some of the social security reforms proposed for the US, most noticeably the progressive personal accounts proposal by Geanakoplos and Zeldes (2008). However, in contrast to the Dutch system, in their proposal the rate of accumulation of pension rights may depend on the existing stock of rights, while the account is held in the form of a security that is marketable and that, moreover, pays an indexed benefit from retirement onwards. In the Netherlands, accumulated claims of workers and retired alike are usually indexed to wage or price inflation. However, there is no legal obligation for pension funds to index those claims. Pension funds rather similar to those in the Netherlands are also under development in Germany. However, the second pillar in the Dutch system is unusually large and provides on average a higher retirement benefit than the first pillar. The Dutch system features one further important peculiarity compared to other industrialized countries, as the majority of the funds in the second pillar are sectoral rather than corporate funds. This implies that employees rather than employers are the risk bearers in the system.

An important indicator of the safety of future second-pillar pensions is the so-called funding ratio, defined as the value of the pension fund's assets divided by its liabilities. A funding ratio above one indicates that the fund has sufficient resources to cover all future pension benefits that follow from existing accumulated pension rights. Exogenous shocks may lower the funding ratio below a critical level that forces the fund's management to take remedial action. For example, negative shocks to the funds' assets can be spread over all generations through reduced indexation of benefits. Overall the second pension pillar thus allows for inter-generational risk sharing. The set of instruments in hand of the fund's management includes not only a change in the degree of indexation, but also a change in the pension contribution rate, and a reduction in nominal pension rights. This third instrument is typically the last resort for pension funds, while a change in indexation either alone or combined with a change in the contribution rate is generally used to eliminate underfunding. Underfunding has become a particularly important problem recently in the Netherlands because of the collapse of stock markets and the fall in the long-run interest rate (implying less heavy discounting of future obligations). Therefore, many pension funds have chosen not to index benefits at the time of this writing (2009). The pension supervisor (the Dutch central bank) determines the speed at which pension buffers have to be restored. During the previous economic downturn (2002 - 2003) when also pension funding ratios became dangerously low, it forced a quick restoration of the buffers, resulting in higher pension contributions, reduced disposable income and allegedly a prolongation of the downturn. Its current attitude seems to be more relaxed, although it requires funds to present credible plans to eliminate underfunding within 
the next five years.

Although alternative policies can have identical implications for the pension funding ratios, their consequences for the welfare of the different generations can differ substantially. While a reduction in indexation spreads the burden of adjustment over all working and retired generations, with the older generations contributing relatively more because of their larger nominal wealth, an increase in contribution rates only directly affects workers. Workers who are further from retirement can expect to contribute more to the restoration of a given degree of underfunding than workers who are close to retirement.

This paper explores the inter- and intra-generational welfare effects of different policies to stabilise pension buffers in an applied many-generation small open-economy OLG model with heterogeneous agents. Specifically, we compare a policy in which (when necessary) the contribution rate is always adjusted first (a "contribution policy") with a policy in which indexation to productivity and price inflation are always adjusted first (an "indexation policy"). In those cases where one instrument is insufficient, the other instrument is also adjusted. In the extreme situation that both instruments together are insufficient, also nominal claims are scaled back by whatever amount is necessary to eliminate the underfunding within the allowed restoration period.

In our stylised economy, the pension system consists of a first pillar PAYG component and a funded second tier. We calibrate the pension system to the Dutch situation. This may seem too specific. However, many countries have reformed or are reforming their pension system, providing a larger role to funded pensions. Owing to the large role of its second pillar, the Dutch system is often used as an example (whether it is followed or not) for reform elsewhere. We calibrate the remaining exogenous parameters according to the standard literature, while we estimate our shock processes on US data over the past decades. In our stochastic simulations, we hit the economy with a variety of unexpected shocks. These may be broadly classified into three categories: demographic uncertainty (the size of newborn generations and survival probabilities that determine life expectancy), economic uncertainty (inflation rate and productivity growth) and financial uncertainty (returns on bonds, equity and residential real estate, as well as the yield curve). There are no individual shocks, only aggregate shocks.

Our stochastic simulations show that pension buffers are highly volatile when the shocks are drawn from realistically modelled multivariate shock processes. In fact, underfunding occurs much more frequently than anticipated by the Dutch pension supervisor and policy intervention is frequently needed to prevent long-run underfunding. Changes in the contribution rate are often supplemented with changes in the indexation rate, and vice versa. By far most of the volatility arises from uncertainty about the yield curve (the rate at which pension liabilities are discounted).

Our two policies have different consequences for different generations. Of the existing generations, on average the youngest prefer the indexation policy, while the older generations prefer the contribution policy. The yet unborn on average also prefer the indexation policy. These outcomes are probably not too surprising, because the young have on average accumulated relatively few nominal claims, so are affected only mildly by changes in the degree of indexation, while as workers they would bear the full burden of a change in pension contributions. By contrast, the retired would be unaffected by a change in pension contributions, but (given their relatively high level of accumulated pension claims) would share substantially in the adjustment burden if it is to be achieved through a change in indexation. One of the merits of this paper, we believe, is that it also quantifies the consequences of alternative policies for different cohorts and individuals with different levels of skills and thus different income-earning capacity. When expressed in terms of a constant difference in rest-of-life consumption the consequences of switching from one to the other policy are generally moderate, though non-negligible (up to a maximum of almost 1\%). They also 
differ rather widely for the various cohort/skill groups and are largest for the highest skill group.

Our contribution builds on three strands of the literature: the literature on applied OLG models (e.g., Auerbach and Kotlikoff, 1987, and Hubbard and Judd, 1987), the literature that studies the welfare properties of unfunded and funded social security systems (e.g., Huggett and Ventura, 1999, and Teulings and de Vries, 2006) and the literature that analyses how a wide variety of unexpected shocks affects the economy (see Imrohoroglu et al., 1995; De Nardi et al., 1999, and Sánchez-Marcos and Sánchez-Mártin, 2006). To the best of our knowledge, this is the first contribution simultaneously dealing with all the aforementioned three aspects. In particular, Bonenkamp and van de Ven (2006) consider a two-generation OLG model, but ignore shocks to inflation and single asset returns. Hari et al. (2007) focus only on the role of mortality risk for the solvency of pension funds. However, simultaneously incorporating demographic, economic and financial shocks is important for the stochastic simulations to produce realistic pension fund behavior.

The remainder of the paper is organised as follows. Section 2 presents the theoretical framework. Section 3 describes the benchmark calibration, and Section 4 shows the main findings from a simulation exercise based on this calibration. Section 5 describes a sensitivity analysis around the model's baseline parameter values and the institutional setting. Section 6 concludes the main text. Finally, the Appendix, Section 7, provides further details on the chosen calibration as well as the estimation of the underlying models used in the stochastic simulation.

\section{The Model}

There are a number of $D$ cohorts alive in any given period $t$. Each cohort $j(=1, \ldots, D)$ consists of $N_{j, t}$ individuals at time $t$, who are distributed in $I$ equally-sized skill groups, $i=1, \ldots, I$. A higher value of $i$ denotes a higher skill level. The skill level of a person determines her income, given her age and the macroeconomic circumstances. Index $j=1, \ldots, D$ indicates the age of the cohort, computed as the amount of time since entry into the labor force. Further, all individuals within a given group earn the same income. Finally, a period in our model corresponds to one year.

\subsection{Cohorts and demography}

We assume that each individual born in period $t-j+1$ (that is, the person has age zero at the start of $t-j+1$ and age one at the end of this period) has an exogenous marginal probability $\psi_{j, t-j+1} \in[0,1]$ of reaching age $j$ (at the end of period $t$ ) conditional on having reached age $j-1$. For example, $\psi_{j, t-j+1}=1$ means that an individual alive at age $j-1$ at the end of period $t-1$ will be alive with certainty at the end of period $t$ and have age $j$ then. Similarly, $\psi_{j, t-j+1}=0$ implies that anyone alive at age $j-1$ at the end of period $t-1$ will surely die before the end of period $t$. Specifically, we assume that $\psi_{j, t-j+1}=0$ for any $j \geq D+1$. To be precise, we assume that individuals can die only at the start of a period, so that the survival of that moment implies that the person reaches the end of the period and receives an income and consumes during that period. We further assume that the cohort of newborn agents in period $t$ is $1+n_{t}$ times larger than the cohort of newborn agents in period $t-1$, that is,

$$
N_{1, t}=\left(1+n_{t}\right) N_{1, t-1} .
$$

In general, we denote with $N_{j, t}$ the size of cohort $j$ in period $t$. This size depends on the history of past survival probabilities. Indeed, for $j=2, \ldots, D$ : 


$$
N_{j, t}=N_{j-1, t-1} \psi_{j, t-j+1}
$$

\section{$2.2 \quad$ Individuals}

Individuals in the same cohort can only differ in terms of their income. Each individual in a given cohort belongs to some skill group $i$, with $i=1, \ldots, I$. We assume that individuals remain in the same skill group over their entire life. Individuals work until the exogenous retirement age $R$ and live for at most $D$ years. During their working life $(j=1, \ldots, R)$, they receive a labour income $y_{i, j, t}$ given by:

$$
y_{i, j, t}=e_{i} s_{j} z_{t},
$$

where $e_{i}, i=1, \ldots, I$ is an efficiency index (linked to the skill level of class $i$ ), $s_{j}, j=1, \ldots, R$ a seniority index (income varies with age) and $z_{t}$ is an exogenous income process:

$$
z_{t}=\left(1+g_{t}\right) z_{t-1}
$$

where $g_{t}$ is the exogenous nominal growth rate of the process and $z_{0}=1$.

Average income across workers is defined as:

$$
y_{t}=\frac{\sum_{j=1}^{R} \frac{N_{j, t}}{I} \sum_{i=1}^{I} y_{i, t, j}}{\sum_{j=1}^{R} N_{j, t}} .
$$

If all workers have identical productivity (i.e. $e_{1}=\ldots=e_{I}=s_{1}=\ldots=s_{I}=1$ ), then $y_{t}=z_{t}$. We make a distinction between $y_{t}$ and $z_{t}$ because the relative sizes of the cohorts may change over time, implying that the ratio $y_{t} / z_{t}$ will fluctuate over time.

\subsection{Social security and accidental bequests}

Social security is based on a two-pillar system. The first pillar is a pay-as-you-go (PAYG) defined benefit (DB) program which pays a flat benefit to every retiree. It is organized by the government, which sets the contribution rate to ensure that the first pillar is balanced on a period-by-period basis. The second pillar is funded and may either be organized by the government or by the private sector. In reality, in the Netherlands some of the parameters of the second pillar are set by the government, while other parameters are set by the pension fund itself. Since we do not explicitly model the objectives of the different policymakers we do not need to make specific assumptions about who sets which parameters. Finally, the government redistributes the accidental bequests left by those who die.

\subsubsection{The first pillar of the social security system}

Each period, an individual of working age pays a mandatory contribution $p_{i, j, t}^{F}$ to the first pillar of the social security system. This contribution depends on the size of his income $y_{i, j, t}$ relative to the thresholds $\delta^{l} y_{t}$ and $\delta^{u} y_{t}$ :

$$
p_{i, j, t}^{F}=\left\{\begin{array}{ll}
0, & \text { if } y_{i, j, t}<\delta^{l} y_{t} \\
\theta_{t}^{F}\left(y_{i, j, t}-\delta^{l} y_{t}\right), & \text { if } y_{i, j, t} \in\left[\delta^{l} y_{t}, \delta^{u} y_{t}\right] \\
\theta_{t}^{F}\left(\delta^{u} y_{t}-\delta^{l} y_{t}\right), & \text { if } y_{i, j, t}>\delta^{u} y_{t}
\end{array}\right\}, \quad j \leq R,
$$


where $\delta^{l}, \delta^{u}$ and $\theta_{t}^{F}$ are policy parameters. In period $t$ a retiree receives a flat benefit that is a fraction $\rho^{F}$ of the average income in the economy:

$$
b_{t}^{F}=\rho^{F} y_{t}
$$

Given the benefit formula in equation (6), each period the contribution rate $\theta_{t}^{F}$ adjusts such that aggregate contributions into the first pillar $P_{t}^{F}$ equal aggregate first-pillar benefits $B_{t}^{F}$ paid out to the retired:

$$
P_{t}^{F}=B_{t}^{F}
$$

where

$$
P_{t}^{F}=\sum_{j=1}^{R} \frac{N_{j, t}}{I} \sum_{i=1}^{I} p_{i, j, t}^{F}
$$

and

$$
B_{t}^{F}=\sum_{j=R+1}^{D} \frac{N_{j, t}}{I} \sum_{i=1}^{I} b_{t}^{F}=b_{t}^{F} \sum_{j=R+1}^{D} N_{j, t} .
$$

Note that under this system an individual earning a low income pays no contributions but still receives the same benefit as an individual with a high income.

\subsubsection{The second pillar of the social security system}

The second pillar consists of a DB funded program. Each period, an individual of working age also pays a mandatory contribution $p_{i, j, t}^{S}$ to this second pillar if her income exceeds the franchise income level $\lambda y_{t}$, where parameter $\lambda$ denotes the franchise as a share of average income. Specifically,

$$
p_{i, j, t}^{S}=\theta_{t}^{S} \max \left\{0, y_{i, j, t}-\lambda y_{t}\right\}, \quad j \leq R,
$$

where $\theta_{t}^{S}$ is a policy parameter. The parameter $\theta_{t}^{S}$ is capped at a maximum value of $\theta^{S, \max }>0$.

A cohort entering retirement at age $R+1$ receives a benefit linked to her entire wage history. Period $t$ benefits for an individual in skill group $i$ of cohort $j$ are given by:

$$
b_{i, j, t}^{S}=M_{i, j, t}, \quad j \geq R+1,
$$

where the accumulated "stock of nominal pension rights" $M_{i, j, t}$ at the end of period $t$ evolves as:

$$
\left.M_{i, j, t}=\left\{\begin{array}{cc}
\left(1-m_{t}\right)\left\{\begin{array}{c}
{\left[1+\iota_{t}\left(\frac{1+g_{t}}{1+\pi_{t}}-1\right)\right]\left(1+\kappa_{t} \pi_{t}\right) M_{i, j-1, t-1}} \\
+\mu \max \left[0, y_{i, j, t}-\lambda y_{t}\right] \\
\left(1-m_{t}\right)\left[1+\iota_{t}\left(\frac{1+g_{t}}{1+\pi_{t}}-1\right)\right]\left(1+\kappa_{t} \pi_{t}\right) M_{i, j-1, t-1},
\end{array}\right.
\end{array}\right\}, \quad \begin{array}{c}
j \geq R \\
j \geq R+1
\end{array}\right\},
$$

where parameter $\mu$ denotes the annual accrual rate of nominal rights as a share of income above the franchise level. The productivity indexation parameter $\iota_{t}$ and the price indexation parameter $\kappa_{t}$ capture the degree of indexation of nominal rights to (approximately) real income growth, $\frac{1+g_{t}}{1+\pi_{t}}-1$, and inflation, $\pi_{t}$, respectively. Indexation policy aims at following total wage growth: however the actual degree of indexation may depend on the financial position of the pension fund. Further, $m_{t}$ captures a proportional reduction in nominal rights that may be applied when the pension buffer is so low that restoration through an increase in contributions and a reduction in indexation is no longer possible. In particular, in our policy rule discussed below we will assume that $m_{t}>0$ only when $\theta_{t}^{S}=\theta^{S, \max }$ and $\iota_{t}=\kappa_{t}=0$. Each individual enters the labour market with zero nominal 
claims. Hence, $M_{i, 0, t-j}=0$, where $M_{i, 0, t-j}$ are the nominal claims at the end of period $t-j$ or the beginning of period $t-j+1$ when the generation enters the labour market at age 0 . Notice that, in contrast to the first-pillar pension benefit, the second-pillar benefit depends on both the cohort and skill level of the individual.

For a given accrual rate and franchise parameters $\mu$ and $\lambda$, for each period $t$ the policymaker chooses the instrument combination $\left\{\theta_{t}^{S}, \iota_{t}, \kappa_{t}\right\}$. The choice of this combination depends on the nominal funding ratio $F_{t}$, which is the ratio between the pension fund's assets, $A_{t}$, and its liabilities, $L_{t}$ :

$$
F_{t}=\frac{A_{t}}{L_{t}}
$$

At the end of period $t$ the pension fund's assets are the sum of the second-pillar contributions from workers in period $t$ minus the second-pillar benefits paid to the retirees in period $t$ plus the pension fund's assets at the end of period $t-1$ grossed up by their return in the financial markets:

$$
A_{t}=\left(\sum_{j=1}^{R} \frac{N_{j, t}}{I} \sum_{i=1}^{I} p_{i, j, t}^{S}-\sum_{j=R+1}^{D} \frac{N_{j, t}}{I} \sum_{i=1}^{I} b_{i, j, t}^{S}\right)+\left(1+r_{t}^{f}\right) A_{t-1}
$$

where

$$
1+r_{t}^{f}=\left(1-z^{e}-z^{h}\right)\left(1+r_{t}^{b}\right)+z^{e}\left(1+r_{t}^{e}\right)+z^{h}\left(1+r_{t}^{h}\right),
$$

is the gross nominal rate of return on the pension fund's asset portfolio with a constant share $z^{e}$ invested in equities, a constant share $z^{h}$ invested in the housing market and the remainder in oneyear bonds. We assume that the net returns on one-year bonds $\left(r_{t}^{b}\right)$, equities $\left(r_{t}^{e}\right)$ and residential housing $\left(r_{t}^{h}\right)$ are exogenous.

The fund's liabilities are the sum of the present values of current and future rights already accumulated by the cohorts currently alive:

$$
L_{t}=\sum_{j=1}^{D} \frac{N_{j, t}}{I} \sum_{i=1}^{I} L_{i, j, t} .
$$

Future benefits are discounted using a term structure of annual nominal interest rates $\left\{r_{k, t}\right\}_{k=1}^{D}$, which we simulate and then normalise (see Section 2.5) to ensure that the interest rate at maturity $k=1$ equals the one-year bond interest rate, $r_{1, t}=r_{t}^{b}$. Hence, the expected present value at time $t$ of current and future benefits of a cohort $j$ in skill group $i$ is

$$
L_{i, j, t}=\left\{\begin{array}{ll}
E_{t}\left[\sum_{l=R+1-j}^{D-j} \frac{1}{\psi_{j, t-j+1}}\left(\prod_{k=0}^{l} \psi_{j+k, t-j+1}\right) \frac{1}{\left(1+r_{l, t}\right)^{l}} M_{i, j, t}\right], & \text { if } j \leq R, \\
E_{t}\left[\sum_{l=0}^{D-j} \frac{1}{\psi_{j, t-j+1}}\left(\prod_{k=0}^{l} \psi_{j+k, t-j+1}\right) \frac{1}{\left(1+r_{l, t}\right)^{l}} M_{i, j, t}\right], & \text { if } j \geq R+1,
\end{array}\right\}
$$

Note that $\psi_{j, t-j+1}$ cancels out in the above equation. When $j \leq R$, furthermore, we discount all future benefits to the current year $t$, but of course they will only be paid out once individuals have retired.

\subsubsection{Accidental bequests}

Accidental bequests do not have any significant bearing on our results. Their only role is to ensure that resources do not "disappear" because people die. All personal (non-pension) financial wealth 
of those who die is collected by the government. The aggregate of these accidental bequests in the economy amounts to:

$$
H_{t}=\sum_{j=2}^{D}\left(1-\psi_{j, t-j+1}\right) \frac{N_{j-1, t-1}}{I} \sum_{i=1}^{I} a_{i, j, t}=\sum_{j=2}^{D} \frac{\left(N_{j-1, t-1}-N_{j, t}\right)}{I} \sum_{i=1}^{I} a_{i, j, t},
$$

where $a_{i, j, t}$ are the assets accumulated by each individual in cohort $j$ in skill group $i$ at the end of period $t-1$ and which become available for collection by the government at the start of period $t$. The government redistributes $H_{t}$ equally over all individuals alive at time $t$, resulting in an individual transfer

$$
h_{t}=\frac{H_{t}}{\sum_{j=1}^{D} N_{j, t}} .
$$

\subsection{Individual decision problem}

In a given period $t$ an individual of cohort $j$ in skill group $i$ chooses a sequence of nominal consumption levels for the rest of her life. Savings are then invested in a portfolio of bond, equity and residential housing. Hence, the individual solves:

$$
V_{i, j, t}=\max _{\left\{c_{i, j+l, t+l}\right\}_{l=0}^{D-j}} E_{t}\left[\sum_{l=0}^{D-j} \frac{\beta^{l}}{\psi_{j, t-j+1}}\left(\prod_{k=0}^{l} \psi_{j+k, t-j+1}\right) u\left(\frac{c_{i, j+l, t+l}}{\prod_{k=0}^{l}\left(1+\pi_{t+k}\right)}\right)\right],
$$

where $u($.$) is the period utility function, which we assume to be of the conventional CRRA format$ with coefficient of relative risk aversion $\gamma$,

$$
u(x)=\frac{x^{1-\gamma}}{1-\gamma},
$$

subject to equations (1)-(15), and the intertemporal budget constraint

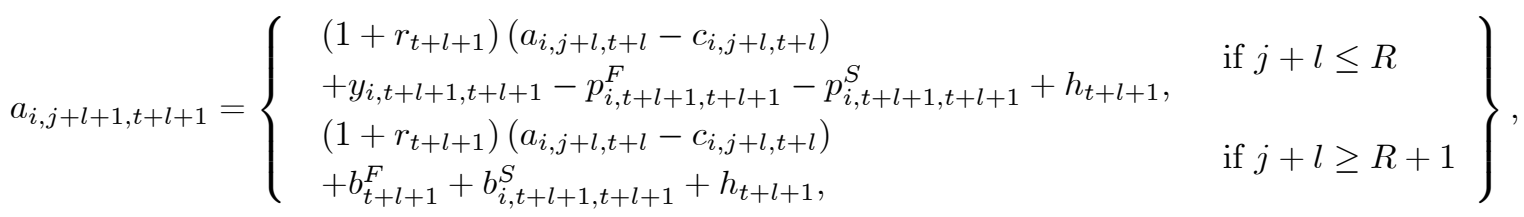

where $a_{i, j+l, t+l}$ are the assets (wealth plus income) in year $t+l$ of an individual in skill group $i$ of cohort $j+l$ and

$$
1+r_{t+l+1}=\left(1-x_{j+l}^{e}-x_{j+l}^{h}\right)\left(1+r_{t+l+1}^{b}\right)+x_{j+l}^{e}\left(1+r_{t+l+1}^{e}\right)+x_{j+l}^{h}\left(1+r_{t+l+1}^{h}\right)
$$

is the overall return on her asset portfolio in period $t+l+1$, the composition of which is age-specific and characterised by the exogenous weights $\left\{x_{j+l}^{e}, x_{j+l}^{h}\right\}$ at the end of period $t+l$. Note that the portfolio choice varies with age, but for given age it is assumed to be fixed across skill categories. The end of next period's assets equal the gross return on this period's assets minus consumption, plus "net income". For the workers, net income is labour income minus social security contributions plus the accidental bequest, while for the retired net income equals the sum of the social security benefits plus the accidental bequest. 
The Euler equation for this problem is

$$
u^{\prime}\left(c_{i, j+l, t+l}\right)=\beta \psi_{j+l+1, t-j+1} E_{t+l}\left[\frac{1+r_{t+l+1}}{1+\pi_{t+l+1}} u^{\prime}\left(\frac{c_{i, j+l+1, t+l+1}}{1+\pi_{t+l+1}}\right)\right] .
$$

In our simulations below we approximate the expectation on the right-hand side of this equation using a Gauss-Legendre quadrature method. The calculation of the expectation makes use of the stochastic multivariate distribution of the shocks.

\subsection{Shocks}

We assume that there are only aggregate, hence no individual-specific shocks. In our model, eight types of aggregate exogenous shocks hit the economy. Specifically, we consider demographic shocks (to the growth rate of the newborns cohort and to the survival probabilities), inflation rate shocks, nominal income shocks (which, together with the inflation shock, produce a shock to the productivity growth rate) and financial market shocks (to bond returns, equity returns, housing returns and the yield curve). Shocks are collected in the vector $\omega_{t}=\left[\epsilon_{t}^{n}, \epsilon_{t}^{\psi}, \epsilon_{t}^{g}, \epsilon_{t}^{\pi}, \epsilon_{t}^{b}, \epsilon_{t}^{e}, \epsilon_{t}^{h}, \epsilon_{2, t}, \ldots, \epsilon_{D, t}\right]^{\prime}$ with elements

- $\epsilon_{t}^{n}$ : shock to the newborn cohort growth rate $n_{t}$

- $\epsilon_{t}^{\psi}$ : a vector of shocks to the set of survival probabilities $\left\{\psi_{j, t-j+1}\right\}_{j=1}^{D}$

- $\epsilon_{t}^{g}$ : shock to the nominal income growth rate $g_{t}$

- $\epsilon_{t}^{\pi}$ : shock to the inflation rate $\pi_{t}$

- $\epsilon_{t}^{b}$ : shock to the one-year nominal bond return $r_{t}^{b}$

- $\epsilon_{t}^{e}$ : shock to the nominal equity return $r_{t}^{e}$

- $\epsilon_{t}^{h}$ : shock to the housing return $r_{t}^{h}$

- $\epsilon_{k, t}, k=2, \ldots, D$ : shock to the return yield at maturity $k>1, r_{k, t}$.

All these shocks affect the size of the funding ratio (equation (11)), whereas only the demographic shocks affect the first pillar of the pension system (equation (7)). As a consequence, the key parameters of the pension system have to be adjusted to restore the balance in the first pillar and to maintain sustainability of the second pillar.

The demographic shocks are independent of each other and of all other shocks (at all leads and lags). The growth rate $n_{t}$ of the newborns cohort depends on deterministic and random components:

$$
n_{t}=n+\epsilon_{t}^{n},
$$

where $n$ is the mean and $\epsilon_{t}^{n}$ the innovation at time $t$, which follows an $\operatorname{AR}(1)$ process with parameter $\varphi$ :

$$
\epsilon_{t}^{n}=\varphi \epsilon_{t-1}^{n}+\eta_{t}^{n}, \quad \eta_{t}^{n \sim} N\left(0, \sigma_{n}^{2}\right) .
$$

The survival probabilities evolve according to a Lee-Carter model (see Appendix 7.2.2 for details): 


$$
\ln \left(1-\psi_{j, t-j+1}\right)=\ln \left(1-\psi_{j, t-j}\right)+\tau_{j}\left(\chi+\epsilon_{t-j+1}^{\psi}\right), \quad \epsilon_{t-j+1}^{\psi} \sim{ }^{\sim}\left(0, \sigma_{\psi}^{2}\right), \quad j=1, \ldots, D .
$$

with $\tau_{j}$ an age-dependent coefficient, $\chi$ a constant growth factor (to describe the historical trend increase in survival probabilities) and $\epsilon_{t-j+1}^{\psi}$ an innovation at time $t-j+1$ that follows an i.i.d. process with variance $\sigma_{\psi}^{2}$.

We allow the shocks to the inflation rate, the nominal income growth, the one-year bond return, the equity return and the housing return to be correlated with each other and over time. These variables feature the following multivariate process:

$$
\left(\begin{array}{c}
\pi_{t} \\
g_{t} \\
r_{t}^{b} \\
r_{t}^{e} \\
r_{t}^{h}
\end{array}\right)=\left(\begin{array}{l}
\pi \\
g \\
r^{b} \\
r^{e} \\
r^{h}
\end{array}\right)+\left(\begin{array}{c}
\epsilon_{t}^{\pi} \\
\epsilon_{t}^{g} \\
\epsilon_{t}^{b} \\
\epsilon_{t}^{e} \\
\epsilon_{t}^{h}
\end{array}\right)
$$

with annual means $\left(\pi, g, r^{b}, r^{e}, r^{h}\right)^{\prime}$, and innovations $\left(\epsilon_{t}^{\pi}, \epsilon_{t}^{g}, \epsilon_{t}^{b}, \epsilon_{t}^{e}, \epsilon_{t}^{h}\right)^{\prime}$ following a VAR(1) process,

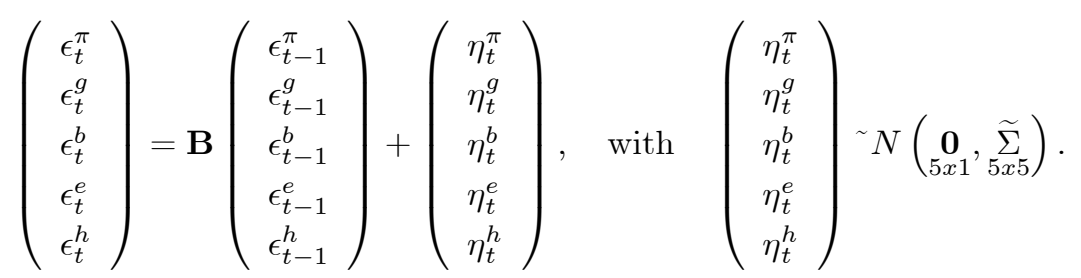

We finally turn to the term structure of annual nominal interest rates (yield curve). We set the interest rate at maturity $k=1$ equal to the one-year bond interest rate arising from the above multivariate process, $r_{1, t}=r_{t}^{b}$. To describe the remaining interest rates of the yield curve, we focus on the rates in excess of the bond interest rate at maturity $1, \widetilde{r}_{k, t}=r_{k, t}-r_{t}^{b}, k=2, \ldots, D$. Following the prevailing literature (see, e.g., Evans and Marshall, 1998; Dai and Singleton, 2000), we model the excess interest rates as a vector autoregressive distributed lag (VADL) process with lag 1:

$$
\left(\begin{array}{c}
\widetilde{r}_{2, t} \\
\widetilde{r}_{3, t} \\
\vdots \\
\widetilde{r}_{D, t}
\end{array}\right)=\boldsymbol{\Gamma}_{0}+\boldsymbol{\Gamma}_{1}\left(\begin{array}{c}
\widetilde{r}_{2, t-1} \\
\widetilde{r}_{3, t-1} \\
\vdots \\
\widetilde{r}_{D, t-1}
\end{array}\right)+\boldsymbol{\Gamma}_{2}\left(\begin{array}{c}
\pi_{t-1} \\
g_{t-1} \\
r_{t-1}^{b} \\
r_{t-1}^{e} \\
r_{t-1}^{h}
\end{array}\right)+\left(\begin{array}{c}
\epsilon_{2, t} \\
\epsilon_{3, t} \\
\vdots \\
\epsilon_{D, t}
\end{array}\right)
$$

with

$$
\left(\begin{array}{c}
\epsilon_{2, t} \\
\epsilon_{3, t} \\
\vdots \\
\epsilon_{D, t}
\end{array}\right) \sim N(\mathbf{0}, \Sigma)
$$

Each period $t$, the excess interest rate at maturity $k, \widetilde{r}_{k, t}, k \geqslant 2$, is a linear combination of deterministic and random components. The deterministic part is a function of several variables at time $t-1$ : the excess interest rates at all maturities $k \geqslant 2$, and the five macro and financial variables whose shocks follow the $\operatorname{VAR}(1)$ process (17). The random part is given by the innovations $\epsilon_{k, t}$, which may be correlated across maturities. 
The average yield curve $\left\{r_{k}\right\}_{k=1}^{D}$ is given by the average yield at maturity $1, r^{b}$, computed above, and the following expression for the interest rates at higher maturities (where we have used $E\left[\tilde{r}_{k, t}\right]=E\left[\tilde{r}_{k, t-1}\right]$ because of stationarity):

$$
\left(\begin{array}{c}
r_{2} \\
r_{3} \\
\vdots \\
r_{D}
\end{array}\right)=\left(\begin{array}{c}
r^{b} \\
r^{b} \\
\vdots \\
r^{b}
\end{array}\right)+\left(\left(I-\boldsymbol{\Gamma}_{1}\right)^{-1}\left(\boldsymbol{\Gamma}_{0}+\boldsymbol{\Gamma}_{2}\left(\begin{array}{c}
0 \\
\\
\\
r^{b} \\
r^{e} \\
r^{h}
\end{array}\right)\right)\right.
$$

\subsection{Policy interventions}

We assume that the government automatically adjusts the contribution rate $\theta_{t}^{F} \in[0,1]$ to maintain a balanced first pension pillar, equation (7). On average, this contribution rate increases over the years along with population ageing.

More policy options are available to affect the funding ratio of the second pillar. Indeed, there are three key parameters: the contribution rate $\theta_{t}^{S} \in\left[0, \theta^{S, \max }\right]$, the two indexation parameters $\left\{\kappa_{t} \geq 0, \iota_{t} \geq 0\right\}$ and, as a last resort, a reduction $m_{t}$ in the nominal pension rights. Policymakers start with a benchmark parameter combination $\left\{\theta^{S}, \kappa, \iota\right\}$ and a funding ratio between the boundaries $1+\xi^{m}$ and $1+\xi^{u}\left(\xi^{m}<\xi^{u}\right)$. There is a third boundary, $1+\xi^{l}\left(\xi^{l}<\xi^{m}\right)$, which is considered to be the level below which there is "underfunding". Policy adjustments take place as follows (the formal rules are in Appendix 7.1). When the funding ratio falls below $1+\xi^{m}$ a long-term restoration plan is started, while when it falls below $1+\xi^{l}$ a short-term restoration plan is started. When the ratio exceeds $1+\xi^{u}$, measures are taken to reduce the funding ratio. Policy is always aimed at moving the funding ratio back into the interval $\left[1+\xi^{m}, 1+\xi^{u}\right]$.

We consider two broad policies for adjustment. In the case of a short-term or a long-term restoration plan, under a contribution policy the contribution rate is always raised first, while under an indexation policy productivity indexation and then price indexation are always reduced first. If this adjustment under either type of policy is insufficient, the other instrument is also adjusted. That is, under the contribution policy further adjustment takes place through reduced productivity and then price indexation, while under the indexation policy further adjustment is made through an increase in the contribution rate. In the rather extreme case that adjustments in the indexation parameters and the contribution rate are jointly insufficient, nominal rights are scaled back by whatever amount is necessary to eliminate the underfunding within the allowed restoration period. In the case of a long-term restoration plan, nominal rights are left untouched. When the funding ratio exceeds $1+\xi^{u}$, missed nominal rights are always given back first, followed by a restoration of missed price and productivity indexation in the case of the indexation policy and a reduction of the contribution rate under the contribution policy. If all these adjustments are still insufficient, the contribution rate is reduced under the indexation policy, while price and productivity indexation are restored under the contribution policy.

The exact policy parameter combination $\left\{\theta_{t+1}^{S}, \kappa_{t+1}, \iota_{t+1}\right\}$ for year $t+1$ is determined in year $t$ on the basis of a projection $\widetilde{F}_{t+1}$ of the funding ratio at time $t+1$, computed from the size of the fund assets $A_{t}$ and liabilities $L_{j, t}=\frac{1}{I} \sum_{i=1}^{I} L_{i, j, t}$ of the various cohorts in year $t$ (averaged over the skill groups), and under the assumption of no further shocks $\left(\omega_{t+1}=\underset{(D+6) x 1}{\mathbf{0}}\right)$. 


\subsection{Welfare measures}

We consider three measures of welfare, one is cohort-specific and the other two are economywide. The first is the intertemporal utility function $V_{i, j, t}$ for skill group $i \in\{1, \ldots, I\}$ and cohort $j \in\{1, \ldots, D\}$ in year $t$. The second measure, $S_{t}^{A}$, is defined as the unweighted average of the intertemporal utilities of all individuals currently alive:

$$
S_{t}^{A}=\sum_{j=1}^{D} \frac{N_{j, t}}{\sum_{j=1}^{D} N_{j, t}} \frac{1}{I} \sum_{i=1}^{I} V_{i, j, t}
$$

The third measure, $S_{t}^{T}$, is defined as the unweighted average of the intertemporal utilities of all alive and unborn individuals:

$$
S_{t}^{T}=\sum_{j=1}^{D} \frac{N_{j, t}}{\sum_{j=1}^{D} N_{j, t}} \frac{1}{I} \sum_{i=1}^{I} V_{i, j, t}+\sum_{s=1}^{\infty} \frac{N_{1, t+s}}{\sum_{j=1}^{D} N_{j, t}} \frac{\frac{1}{I} \sum_{i=1}^{I} V_{i, 1, t+s}}{(1+q)^{s}}
$$

with $q$ the discount rate applied to future generations' welfare. In the simulations, we truncate the computation of welfare to 250 unborn generations, as the discounted welfare of subsequent generations is negligible in equation (18). ${ }^{1}$ Note that in equation (18) the size of any unborn generation is normalised to the size of the population alive in year $t$.

To ease the interpretation of the three measures $V_{i, j, t}, S_{t}^{A}$ and $S_{t}^{T}$, we report them in terms of constant consumption flows. As regards the cohort-specific measure $V_{i, j, t}$, we define "certainty equivalent consumption" $C E C_{i, j, t}$ for skill group $i \in\{1, \ldots, I\}$, cohort $j \in\{1, \ldots, D\}$ in year $t$, as the certain, constant consumption level over the remainder of the cohort's lifetime that yields a level of the utility function identical to the level of the utility function obtained under the relevant scenario. Hence,

$$
C E C_{i, j, t}=u^{-1}\left(\frac{V_{i, j, t}}{E_{t}\left[\sum_{l=j}^{D} \frac{\beta^{l-j}}{\psi_{j, t-j+1}}\left(\prod_{k=0}^{l-j} \psi_{j+k, t-j+1}\right)\right]}\right)
$$

In a similar vein, for the economy-wide measures we define the constant consumption flow

$$
C_{t}^{A}=u^{-1}\left(\frac{S_{t}^{A}}{\sum_{l=\bar{J}+1}^{D} \frac{\beta^{l-(\bar{J}+1)}}{\psi_{\bar{J}+1, t-\bar{J}}}\left(\prod_{k=0}^{l-(\bar{J}+1)} \psi_{(\bar{J}+1)+k, t-\bar{J})}\right)}\right) .
$$

and

\footnotetext{
${ }^{1}$ That is, $1 /(1+q)^{s} \cong 0$ for $s>250$.
} 


$$
C_{t}^{T}=u^{-1}\left(\frac{S_{t}^{T}}{\sum_{l=\bar{J}+1}^{D} \frac{\beta^{l-(\bar{J}+1)}}{\psi_{\bar{J}+1, t-\bar{J}}}\left(\prod_{k=0}^{l-(\bar{J}+1)} \psi_{(\bar{J}+1)+k, t-\bar{J}}\right)}\right) .
$$

of an agent with the average age $\bar{J}$ in the economy in year $t$,

$$
\bar{J}=\text { integer }\left[\frac{\sum_{j=1}^{D} j N_{j, t}}{\sum_{j=1}^{D} N_{j, t}}\right],
$$

where integer [.] is the function that generates the largest integer smaller than or equal to the number inside the square brackets. Note that this is the constant consumption stream of a person of age $\bar{J}$ that gives her a utility equal to social welfare $S_{t}$. It is not the constant consumption stream that gives a person of age $\bar{J}$ the utility level that he has under the relevant policy.

We also define the skill-group $i$ specific counterparts $S_{i, t}^{A}$ and $S_{i, t}^{T}$ to $S_{t}^{A}$ and $S_{t}^{T}$ :

$$
S_{i, t}^{A}=\sum_{j=1}^{D} \frac{N_{j, t}}{\sum_{j=1}^{D} N_{j, t}} V_{i, j, t} \text { and } S_{i, t}^{T}=\sum_{j=1}^{D} \frac{N_{j, t}}{\sum_{j=1}^{D} N_{j, t}} V_{i, j, t}+\sum_{s=1}^{\infty} \frac{N_{1, t+s}}{\sum_{j=1}^{D} N_{j, t}} \frac{V_{i, 1, t+s}}{(1+q)^{s}} .
$$

Using $S_{i, t}^{A}$ and $S_{i, t}^{T}$, we calculate (analogous to (20) and (21)) skill-group specific constant consumption flows $C_{i, t}^{A}$ and $C_{i, t}^{T}$.

\subsubsection{Comparison of policy scenarios}

We evaluate welfare under a scenario A relative to the welfare under a scenario B. The two scenarios are identical in everything apart from the policies adopted in the second pension pillar. In the following, scenario A implements the indexation policy, while scenario B implements the contribution policy. In both scenarios the parameters are initially identical and equal to those in the benchmark calibration. They keep unchanged in the following years as long as the funding ratio remains between $1+\xi^{m}$ and $1+\xi^{u}$. Once the funding ratio falls below $1+\xi^{m}$ or rises above $1+\xi^{u}$, the parameters change according to the specific policy in place. They then vary on the basis of the fluctuations of the funding ratio.

We consider four measures of welfare comparison between the two policies. A first natural measure is the constant percentage difference in certainty equivalent consumption between the two scenarios. For each skill group and cohort in a given period this measure is computed as:

$$
\Delta C E C_{i, j, t}(A, B) \equiv \frac{C E C_{i, j, t}(B)-C E C_{i, j, t}(A)}{C E C_{i, j, t}(A)},
$$

where $C E C_{i, j, t}(s)$ denotes the value of $C E C_{i, j, t}$ under scenario $s \in\{A, B\}$. We consider three further measures to compare welfare between the two policies in a single number. One is the "majority support" for policy $\mathrm{B}$, that is the share of those alive at $t=1$ that are better off under $\mathrm{B}$ rather than A:

$$
D_{t}(A, B) \equiv \frac{1}{\sum_{j=1}^{D} N_{j, t}} \sum_{j=1}^{D} \frac{N_{j, t}}{I} \sum_{i=1}^{I} \mathbf{1}\left\{C E C_{i, j, t}(B)>C E C_{i, j, t}(A)\right\}
$$


where $\mathbf{1}\{$.$\} is an indicator function that assigns a value of one (zero) if the condition inside the$ curly brackets holds (does not hold). The final two measures of welfare comparison are the "social welfare gain" from using policy B rather than policy A, excluding, respectively including, the welfare of the unborn generations:

$$
\begin{aligned}
& \Delta C_{t}^{A}(A, B) \equiv \frac{C_{t}^{A}(B)-C_{t}^{A}(A)}{C_{t}^{A}(A)} \\
& \Delta C_{t}^{T}(A, B) \equiv \frac{C_{t}^{T}(B)-C_{t}^{T}(A)}{C_{t}^{T}(A)} .
\end{aligned}
$$

\section{Calibration and details of the simulation}

We follow the standard literature and calibrate the exogenous parameters of the model to reproduce the main features of the US economy. However, the pension arrangements are calibrated to the Dutch situation. Table 1 summarises our benchmark calibration.

We assume that the economically active life of an agent starts at age 25. Individuals work for $R=40$ years until they reach age 65 . They live for at most $D=75$ years, that is until age 100 . Their coefficient of relative risk aversion is set to $\gamma=2$, in accordance with a large part of the macroeconomic literature. The discount factor is set to $\beta=0.98$, slightly above the usual choice of 0.96 because individuals also take into account their survival probabilities. To compute the welfare measure (18) we try several discount rates of the utility of unborn generations. We find no qualitative differences and in what follows we report results based on $q=4 \%$. The age-dependent portfolio composition $\left\{x_{j}^{e}, x_{j}^{h}\right\}_{j=1}^{D}$ is taken from mean values from the 2007 wave of the Survey of Consumer Finances (SCF, 2009). ${ }^{2}$ Portfolio composition is reported by age groups, and we interpolate the data using the spline method. We keep the portfolio weights constant for ages as of 90. The efficiency index $\left\{e_{i}\right\}_{i=1}^{I}$ is given by the income deciles in the US for year 2000 taken by the World Income Inequality Database (WIID, 2008). We normalise the index to have an average of 1 . The seniority index $\left\{s_{j}\right\}_{j=1}^{I}$ uses the average of Hansen's (1993) estimation of median wage rates by age group. We take the average between males and females and interpolate the data using the spline method.

The exogenous social security parameters are specifically calibrated to the Dutch situation. For the first social security pillar we set the benefit scale factor $\rho^{F}=17 \%$ to generate a realistic average replacement rate of $30.40 \%$. The Dutch Tax Office ("Belastingdienst") reports for 2008 a maximum income assessable for first-pillar contributions of EUR 3, 850.40 per month. We therefore set our upper income threshold for contributions $\delta^{u}=1.10$, roughly equal to $3,850.40 * 12 / 42,403$, where EUR 42, 403 is our imputation of the economy's average income as of 2008. ${ }^{3}$ The lower income threshold is set to $\delta^{l}=0.56$, in such a way as to generate a starting contribution rate $\theta_{1}^{F}=16.42 \%$, consistently with the reality. For the second social security pillar, historically the accrual rate has been between 1.5 and $2 \%$, and most frequently at $1.75 \%$. We therefore consider $\mu=1.75 \%$ and

\footnotetext{
${ }^{2}$ We aggregate assets into three categories: bonds (transaction accounts, certificates of deposit, savings bonds, and bonds), equities (stocks, investment funds, cash value of life insurance, other assets) and housing (residental properties).

${ }^{3}$ In Eurostat the most recent statistic on average income in the Netherlands refers to year $2005 . \quad$ The same source also provides the minimum income until year 2008. Exploiting the correlation between average and minimum income, we run an OLS regression of average income over time and minimum income. As a result, we predict the average income of year 2008 to be EUR 42, 403 .
} 
set the franchise to $\lambda=0.33$, to generate a realistic average replacement rate of $37.60 \%$. In our simulations we consider a short-term restoration period of $K^{s}=5$ years when the pension buffer falls below $1+\xi^{l}$ and a long-term restoration period of $K^{l}=15$ years when the pension buffer falls below $1+\xi^{m}$, but remains at or above $1+\xi^{l}$. Further, we set the thresholds $\left\{\xi^{l}, \xi^{m}, \xi^{u}\right\}$ for the buffer at $\left\{\xi^{l}, \xi^{m}, \xi^{u}\right\}=\{5 \%, 25 \%, 60 \%\}$.

We assume a constant portfolio composition of the pension fund's investments and set $\left\{z^{e}, z^{h}\right\}=$ $\{45 \%, 5 \%\}$. Our choice for $\left\{z^{e}, z^{h}\right\}$ corresponds to the balance sheet average for the Dutch pension funds over the period 1996 - 2005 (source: Dutch central bank, DNB, 2009). Because the various assets in the pension fund's portfolio generally have different realized returns, at the end of each period $t$ the portfolio is reshuffled such that the fund enters the next period $t+1$ again with the original portfolio weights $\left\{z_{t+1}^{e}, z_{t+1}^{h}\right\}=\{45 \%, 5 \%\}$.

Finally, we set the starting levels of the indexation parameters to $\kappa_{1}=\iota_{1}=100 \%$ (hence the pension fund provides full indexation to nominal wages). The starting second-pillar contribution rate is set in such a way that aggregate contributions at time 1 coincide with aggregate benefits in the absence of shocks. The rate that satisfies this condition is $\theta_{1}^{S}=17.58 \%$, which is close to the average actual contribution rate in the Netherlands. We then choose initial assets $A_{0}$ that generate an initial funding ratio $F_{1}$ of $130 \%$ in the absence of shocks. ${ }^{4}$ The contribution rate is capped at $\theta^{S, \max }=25 \%$.

The deterministic growth rate of the newborn cohort, $\mu=0.47362 \%$, is the average growth from a regression using 20 observations on the annual variation in the number of births in the US between 1986 and 2005 (the source is the Human Mortality Database, HMD, 2009); details on the regression are in Appendix 7.2. This Appendix also describes our calibration of the survival probabilities based on the Lee-Carter model (Lee and Carter, 1992). The combination of survival probabilities and birth rates determines the size of each cohort. The starting value of the old-age dependency ratio (i.e., the ratio of retirees over workers) is $25.23 \%$, in line with OECD statistics for 2005 .

\footnotetext{
${ }^{4}$ Initial assets $A_{0}$ are 1.9088 times the total income in the economy. This is on the high side compared to the actual Dutch situation. However, in our model every worker participates in the pension fund, while in the Netherlands this is only part (though a majority) of those who are employed. Moreover, a large fraction of the workers has his pension arranged through insurance companies, while the self-employed do not participate in pension funds either (they have the possibility to build up their pension through an insurance company, but the financial reserves of insurance companies are not considered part of the pension buffers).
} 
Table 1. Calibration of the exogenous parameters

\begin{tabular}{|c|c|c|}
\hline Symbol & Meaning & Calibration \\
\hline \multicolumn{3}{|c|}{ General setting } \\
\hline$D$ & Number of cohorts (= maximum death age -25$)$ & 75 \\
\hline$R$ & Number of working cohorts (= retirement age -25$)$ & 40 \\
\hline$\gamma$ & Relative risk aversion parameter & 2 \\
\hline$\beta$ & Discount factor & 0.98 \\
\hline$q$ & Unborn generation discount rate & $4 \%$ \\
\hline$\left\{x_{j}^{e}, x_{j}^{h}\right\}_{j=1}^{D}$ & Household portfolio composition & SCF (2009) \\
\hline$\left\{e_{i}\right\}_{i=1}^{I}$ & Efficiency index & WIID (2008) \\
\hline$\left\{s_{j}\right\}_{j=1}^{I}$ & Seniority index & Hansen (1993) \\
\hline \multicolumn{3}{|c|}{ First pillar pension parameters } \\
\hline$\rho^{F}$ & Benefit scale factor & $17 \%$ \\
\hline$\left\{\delta^{l}, \delta^{u}\right\}$ & Income thresholds in the contribution formula & $\{0.56,1.10\}$ \\
\hline \multicolumn{3}{|c|}{ Second pillar pension parameters } \\
\hline$\mu$ & Accrual rate & $1.75 \%$ \\
\hline$\lambda$ & Franchise share & 0.33 \\
\hline$\left\{z^{e}, z^{h}\right\}$ & Fund portfolio composition & $\{45 \%, 5 \%\}$ \\
\hline$\left\{\xi^{l}, \xi^{m}, \xi^{u}\right\}$ & Buffer thresholds & $\{5 \%, 25 \%, 60 \%\}$ \\
\hline$\left\{K^{S}, K^{L}\right\}$ & Restoration periods & $\{5,15\}$ \\
\hline$\left\{\kappa_{1}, \iota_{1}\right\}$ & Starting indexation & $\{100 \%, 100 \%\}$ \\
\hline$\theta_{1}^{S}$ & Starting contribution rate & $17.58 \%$ \\
\hline$\theta^{S, \max }$ & Upper bound on contribution rate & $25 \%$ \\
\hline
\end{tabular}

Crucial is the calibration of the average annual values of price inflation, nominal income growth and the bond, equity and residential real estate returns. Table 2 lists our benchmark calibration based on the US economy. We choose the values loosely following the literature (see, e.g., Brennan and Xia, 2002, and Van Ewijk et al., 2006) and set the average inflation rate at $\pi=2 \%$, the average nominal income growth rate at $g=3 \%$ (which corresponds to an average annual real productivity growth rate of $1 \%$ ), the average one-year bond interest rate at $r^{b}=3 \%$, and the average residential real estate return at $r^{h}=4 \%$. The average equity return is set at $r^{e}=5.625 \%$ to generate a funding ratio that is stable over time in the absence of shocks and policy parameter changes. ${ }^{5}$ Innovations in these five variables follow the $\operatorname{VAR}(1)$ process described in Appendix 7.2.3. Appendix 7.2.4 provides details on the estimation of the parameters of the process for the yield curve $\left\{r_{k, t}\right\}_{k=1}^{D}$.

Table 2. Calibration of the annual averages of the random variables

\begin{tabular}{ccc}
\hline \hline Symbol & Description & Calibration \\
\hline$\pi$ & Inflation rate & $2 \%$ \\
$g$ & Nominal income growth rate & $3 \%$ \\
$r^{b}$ & One-year nominal bond return & $3 \%$ \\
$r^{e}$ & Equity return & $5.625 \%$ \\
$r^{h}$ & Residential real estate nominal return & $4 \%$ \\
\hline Note: the Appendix reports the estimates of the stochastic components
\end{tabular}

\footnotetext{
${ }^{5}$ The selected average equity return is well below its historical value, but is a fairly common choice in the literature (see, e.g., Cocco et al., 2005, and Gomes and Michaelides, 2005).
} 
To obtain the optimal consumption rules from equation (16) we solve the individual decision problem recursively by backward induction using the method of "endogenous gridpoints" (Carroll, 2006). Shocks to the inflation rate, the income growth rate and the bond, equity and real estate returns introduce through equation (17) five state variables into the model. To avoid the curse of dimensionality caused by having too many state variables, we determine the optimal rule in year $t$ under the assumption that the shocks in year $t-1$ are all equal to $0, \epsilon_{t-1}^{\pi}=\epsilon_{t-1}^{g}=\epsilon_{t-1}^{b}=\epsilon_{t-1}^{e}$ $=\epsilon_{t-1}^{h}=0$. We approximate the random variable distributions by means of a Gauss-Legendre quadrature method (see Tauchen and Hussey, 1991), and discretise the state space using a grid of 100 points with triple exponential growth. ${ }^{6}$ For points that lie outside the state space grid, we use linear extrapolation to derive the optimal rule.

We simulate $N=1,000$ times a sequence of vectors of unexpected shocks over $2 D-1+250=399$ years, drawn from the joint distribution of all the shocks. Our welfare calculation is based on the economy as of the $D^{t h}$ year in the simulation. Hence, we track only the welfare of the cohorts that are alive in that year, implying that those that die earlier are ignored, and we track the welfare of cohorts born later, the latest one dying in the final period of the simulation. Hence, the total number of years of one simulation run equals the time distance between the birth of the oldest cohort that we track and the death of the latest unborn cohort that we track. At each moment there are $D$ overlapping generations. For the sake of simplicity, we relabel the $D^{t h}$ year in the simulation as $t=1$. The purpose of simulating the first $D-1$ years is to simply generate a distribution of the assets held by each cohort at the end of $t=0$.

In each simulation run, we assume that the ageing process stops after $t=40$. That is, mortality rates at any given age no longer fall. This assumption is in line with the fact that some important ageing studies, such as those by the Economic Policy Committee and European Commission (2006) and the United Nations (2009), only project ageing (and its associated costs) up to 2050, hence roughly 40 years from now. Moreover, it is hard to imagine that mortality rates continue falling for many more decades at the same rate as they did in the past. In particular, many of the common mortal diseases have already been eradicated, while it will become more and more difficult to treat remaining lethal diseases. Effective treatment of those diseases will also surely be held back by the fact that the share of national income that can be spent on health care is bounded.

To allow for the cleanest possible comparison between the contribution and indexation policies, we use the same shock series under both policies, while, moreover, during the initialisation phase of each simulation run no policy responses occur (that is, there is constant and complete indexation and the contribution rate is kept constant). Hence, the starting situation at the end of $t=0$ or beginning of $t=1$ (before choices are made) is identical in each run under the two policies. Because welfare depends on the size of the buffer after the initialisation period in the simulation run, we reset the stock of pension fund assets such that the buffer at the end of $t=0$ equals $130 \%$. Finally, the process $z_{t}$ is re-normalised to unity at the end of $t=0$ and the nominal pension claims of the various cohorts are rescaled accordingly. At the start of the preceding $D-1$ dummy years, liabilities are set at the steady state values implied by the income level at that moment. They are computed using (10) under the assumption of no shocks (i.e. expectations are treated as if they are realised).

\footnotetext{
${ }^{6}$ We create an equally-spaced grid of the function $\log (1+\log (1+\log (1+s)))$, where $s$ is the state variable. The grid with "triple exponential growth" applies the transformation $\exp (\exp (\exp (x)-1)-1)-1$ to each point $x$ of the equally-spaced grid. This transformation brings the grid back to the original scale of the state variable, but determines a higher concentration on the low end of possible values. A grid with triple exponential growth is more efficient than an equally-spaced grid as the consumption function is more sensitive to small values of the state variable.
} 


\section{Benchmark simulations}

\subsection{Introduction}

The simulation analysis under the two types of policies is conducted in two steps. In Section 4.2 we explore the behaviour of the pension funding ratio, the instruments and welfare when shocks are absent, while Section 4.3 reports the main findings for the full stochastic simulation based on the benchmark calibration.

\subsection{Simulation without shocks}

In the absence of shocks, equity returns and population ageing drive the trend of the funding ratio. Panel a of Figure 1 shows the trend with $\chi=0$ (no growth factor in survival probabilities) under three scenarios: when (i) the policy parameters are fixed to their benchmark values, (ii) the fund applies an indexation policy, and (iii) the fund applies a contribution policy. Keeping the policy parameters fixed (thus ignoring the funding ratio threshold $1+\xi^{u}$ ), the funding ratio tends to rise gradually over time (solid line), driven by the relatively high rate of return on the fund assets as compared to the nominal income growth rate. If we instead set the parameter $\chi$ to its benchmark level, and therefore allow for a gradual growth in survival probabilities, the funding ratio under unchanged policy parameters tends to fall over the relevant years (see Panel b of Figure 1). The fall is however modest and, taking into account all years in the simulation run, the ratio is never below 1.13 (as opposed to an initial level of 1.30). Hence, the effects of population ageing and relatively high portfolio returns offset each other.

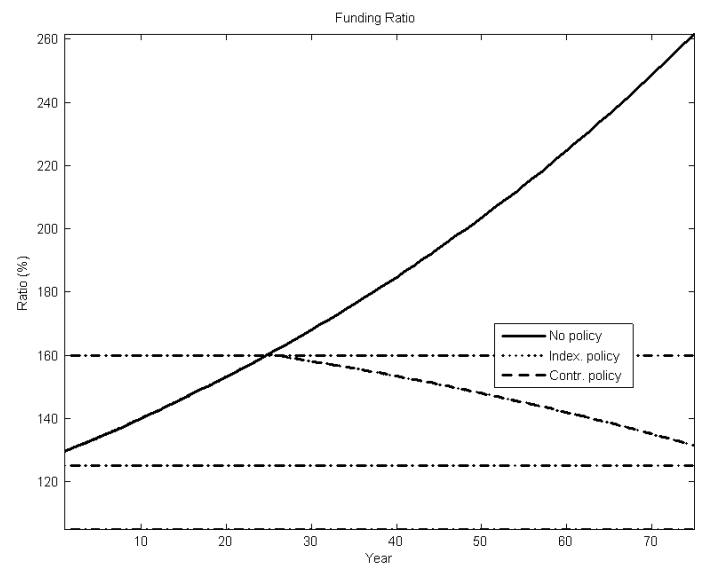

a. Without population ageing

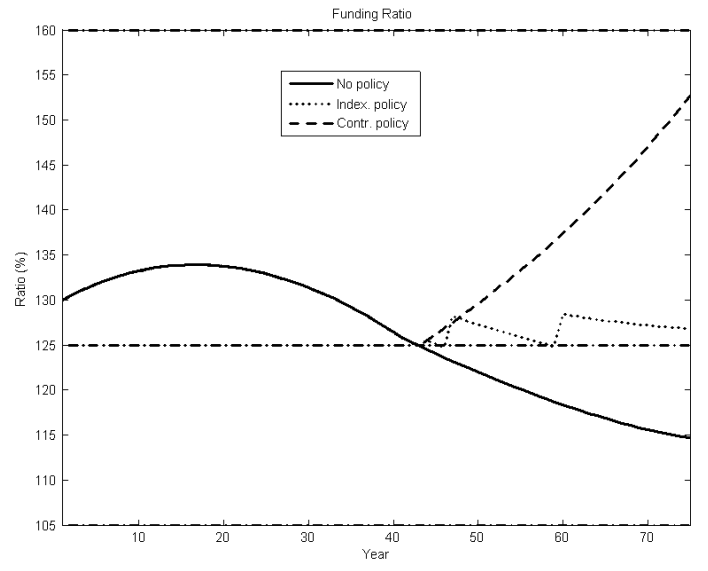

b. With population ageing

Figure 1. Funding ratio in the absence of shocks

Under either an indexation or contribution policy the funding ratio becomes stable in the region comprised between $1+\xi^{m}$ and $1+\xi^{u}$. In panel a of Figure 1 the funding ratio evolves identically under both policies. ${ }^{7}$ In panel b of Figure 1 (with growth in the survival probabilities), the funding ratio is temporarily higher under the contribution policy. Figure 2 below shows the policy parameters in an economy with population ageing and explains why this is the case. When a

\footnotetext{
${ }^{7}$ From the start onwards there is full indexation to productivity and price changes. As soon as $1+\xi^{u}$ is reached, the contribution rate is reduced (both under the indexation and the contribution policy). This momentarily prevents the funding ratio from rising above $1+\xi^{u}$. However, at this new parameter combination, the ageing process dominates and the funding ratio starts to decline (until the $1+\xi^{m}$ is crossed and a long-term restoration plan is started).
} 
policy change is made necessary (that is, when the funding ratio falls below $1+\xi^{m}$ ), contributions rise under the contribution policy, while productivity and sometimes price indexation fall under the indexation policy. In this case without shocks, deviations from the target $1+\xi^{m}$ are small and under neither policy there is a need to simultaneously change the contribution and indexation parameters. However, it is worth to point out that, while the contribution policy prescribes only one large adjustment in the contribution rate, the indexation policy produces more frequent adjustments in the indexation parameters. As a result, only the funding ratio under contribution policy keeps on increasing until the threshold $1+\xi^{u}$ is reached.

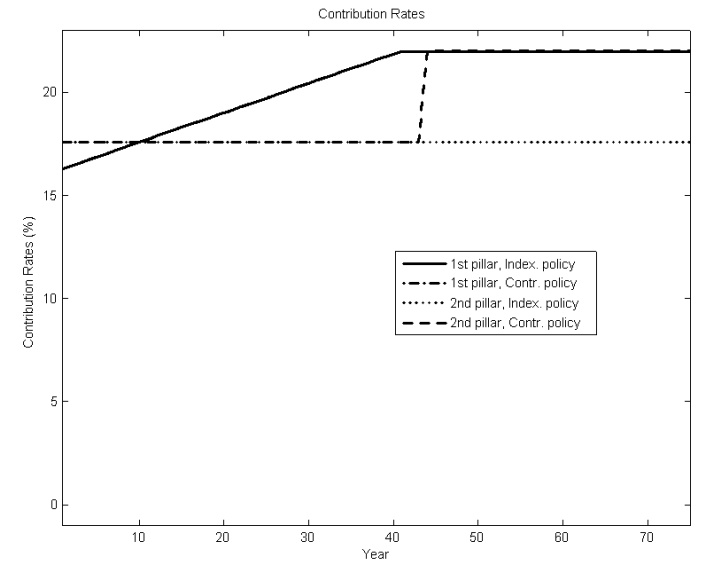

a. Contribution rates

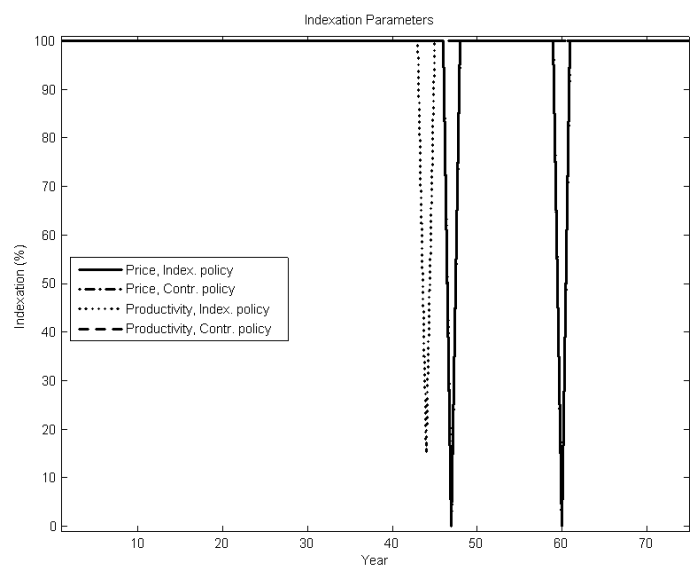

b. Indexation parameters

Figure 2. Alternative policies in the absence of shocks

The solid line in Figure 3 shows the cohort and skill group-specific difference in CEC between the two policies (as defined in equation (22)). Positive values indicate a preference for the contribution policy. More specifically, a value of $\triangle C E C_{i, j, 1}$ equal to $\mathrm{X} \%$ indicates that cohort $j$ of skill group $i$ enjoys $\mathrm{X} \%$ more units of certainty equivalent consumption over the rest of its life under the contribution policy than under the indexation policy. The figure for "all skill groups" is computed as the average of the CECs across all the individual skill groups. Welfare differences in this scenario without shocks are limited to no more than $0.09 \%$ of rest-of-life consumption. Cohorts of age above 60 have no preference for either policy because the first instrument adjustment, whether it is an increase in the contribution rate or a reduction in indexation, only takes place after forty years, i.e. when these older cohorts have already died. 


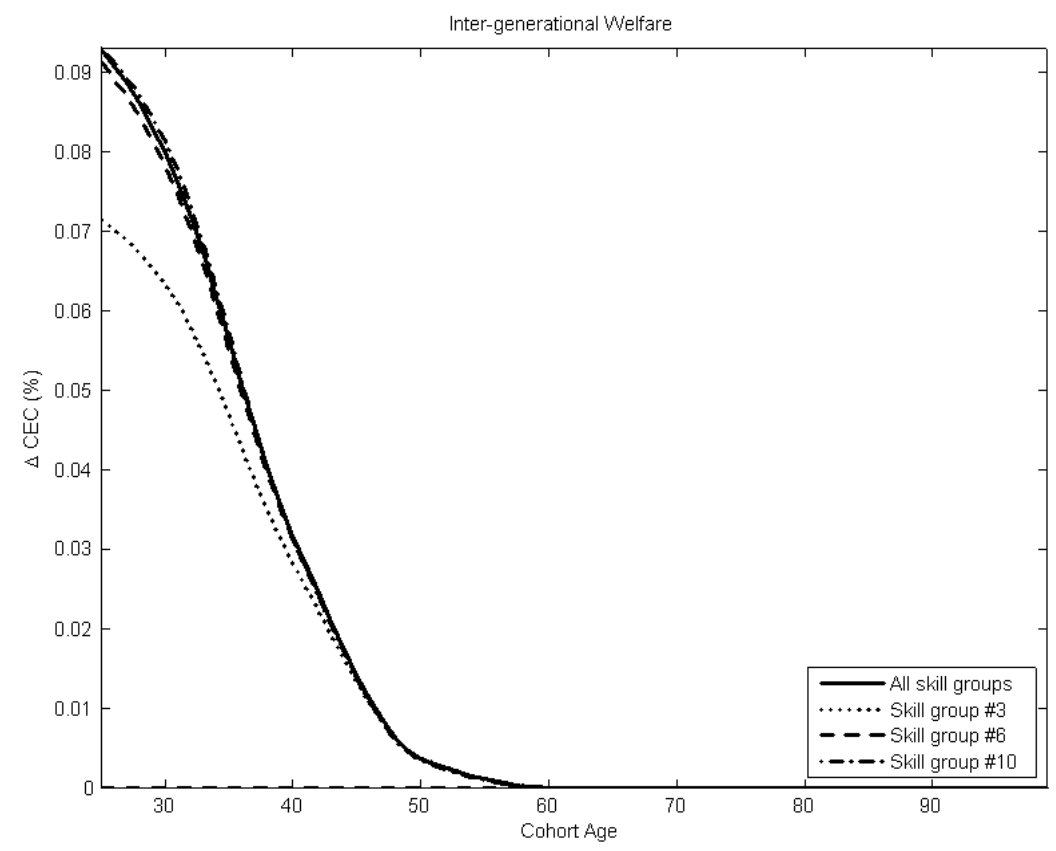

Figure 3. Contribution vs. indexation policy - no shocks

$\triangle C E C>0$ : better-off with the contribution policy

The intuition for generations younger than roughly 60 at $t=1$ preferring the contribution policy is as follows. First, if a fall in the funding ratio is stemmed by a reduction in indexation, all existing generations contribute to restoration of the funding ratio, while an increase in the contribution rate only affects workers. Ceteris paribus, on average workers would be in favour of reducing indexation. However, part of the adjustment burden is shifted onto generations that are born in the future and whose welfare is not counted. With an indexation policy the burden of adjustment on the current wokers continues until they die (as missed indexation will never be restored in their lifetime), while with a contribution policy the adjustment burden vanishes when the worker retires and it is the younger and future workers that continue to contribute to the restoration. For the workers alive at $t=1$ (and younger than roughly 60), it is the larger involvement of the future workers that gives the contribution policy a small edge over the indexation policy. We indeed obtain that a share $D_{1}=66.94 \%$ of the alive population support a contribution policy, which generates a small welfare gain of $\Delta C_{1}^{A}=0.04 \%$ compared to the indexation policy. However, taking into account future generations, a contribution policy instead slightly reduces welfare $\left(\Delta C_{1}^{T}=-0.07 \%\right)$.

The relative preference for a contribution policy is smaller the older is a generation of workers at $t=1$. The intuition is that older workers (though younger than roughly 60 ) will experience only a very brief period of reduced indexation or a higher contribution rate. This difference between the two policies over a short period is expressed in terms of a constant consumption difference over a large number of remaining years of life as of $t=1$.

For the different skill groups (with higher skill levels denoted by a higher group number), qualitatively the cohort-profile of the policy comparison is identical. However, the size of the welfare difference depends on the income level. The (relative) desirability of a contribution policy is lower for the lowest skill groups. ${ }^{8}$

\footnotetext{
${ }^{8}$ In Figure 3 we neglect the first two skill classes as individuals in these groups are too poor to receive a reasonable benefit from the second-pillar system.
} 


\subsection{Stochastic simulation}

Now we turn to the stochastic simulation of our model for the benchmark parameter setting. In each period an entire new shock vector as described in Section 2.6 is drawn and shocks are allowed to propagate over the lifespan of each cohort. Figure 6 displays the median (over the $N$ runs) size of the funding ratio. ${ }^{9}$ When the policy parameters are kept constant throughout, the buffer moves along a downward trend. When a policy reaction takes place, the policy parameters are adjusted to gradually restore the funding ratio. Our two policies, the indexation policy and the contribution policy indeed manage to keep the median funding ratio above the threshold $1+\xi^{m}$. However, the development of the median funding ratio (see Figure 4) hides a wide dispersion of individual paths for the funding ratio. Over all the observations simulated for the relevant years (1,000 times 75 years), the buffer falls below $1+\xi^{l}$ in no more than $21 \%$ of the cases under both policies, against the $45 \%$ observed under no policy intervention.

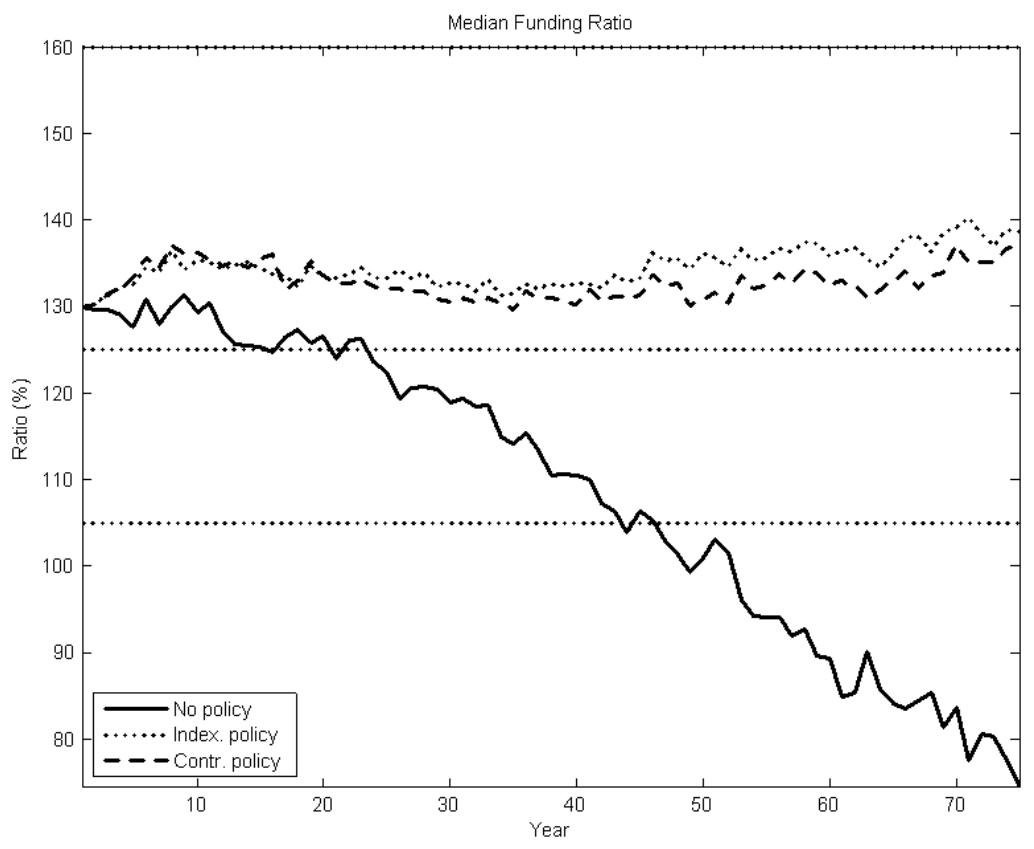

Figure 4. Median funding ratio

Adjustments in the second-pillar parameters not only restore the buffer, but also reduce the volatility of the funding ratio. In Figure 5 we report the median coefficient of variation (quartile deviation over median) resulting from our simulations in the three cases. This measure is computed for each period over the cross-section of simulation runs. The upward-sloping trend of the coefficient when the policy parameters are kept constant suggests that the funding ratio fluctuates more when the buffer is farther from its target. However, the volatility of the funding ratio stabilises at around $19 \%$ under our two policies.

\footnotetext{
${ }^{9}$ We report the median size rather than the average size, because the former measure is not affected by the few extreme outcomes generated in our simulations.
} 


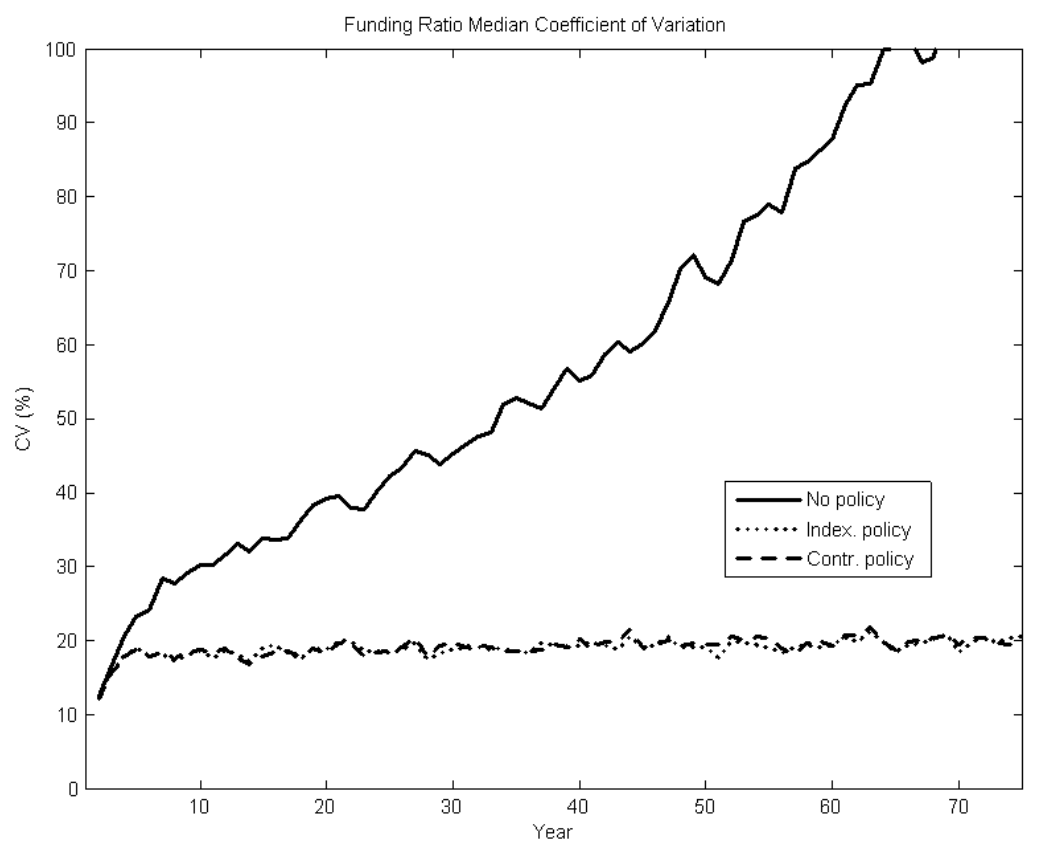

Figure 5. Funding ratio volatility

The median policy responses to unexpected shocks are shown in Figure 6. Panel a. of the figure shows the contribution rates. The first-pillar contribution rate is identical in both policies and shows a clear upward-sloping trend, from $16 \%$ in year 1 to $22 \%$ in year 40 consistent with the ageing of the society (which in our model depends on the trend increase in the survival probabilities, and is stopped after year 40).

The second-pillar contribution rate (the dashed lines) instead reveals a different development under the two policies. Under the contribution policy, it starts increasing immediately after the funding ratio falls below $1+\xi^{m}$. Instead under the indexation policy, the median contribution rate increases later. Both policies end up generating a median contribution rate of $25 \%$ after 15 years. The average contribution rate under indexation (contribution) policy is 19.11 (17.27) percent. Panel b. of Figure 6 shows the median indexation parameters. Under the indexation policy, we observe in early years a reduction in both productivity and price indexation. The reduction in indexation - especially price indexation - arises later under the contribution policy. On average, price and productivity indexation are larger under indexation policy rather than contribution policy (95.12 and 81.18 against 91.22 and 70.30 percent). Notice that an indexation policy produces on average larger indexation parameters and contribution rates than a contribution policy. The former is the result of the restoration of lost indexation when the funding ratio exceeds $1+\xi^{u}$.

However, the medians shown in Figure 6 hide a lot of dispersion of the instruments. The withinyear standard deviation of the parameters is very large (around $10 \%$ for the contribution rates, and around $200 \%$ for the indexation parameters, with a peak of $259.31 \%$ for productivity indexation under indexation policy). An adjustment in only indexation or the contribution rate is made in $29 \%$ and $14 \%$ of the simulations respectively under the indexation and the contribution policies. A change in both instruments is needed in around $4 \%(10 \%)$ of the cases under an indexation (contribution) policy. 


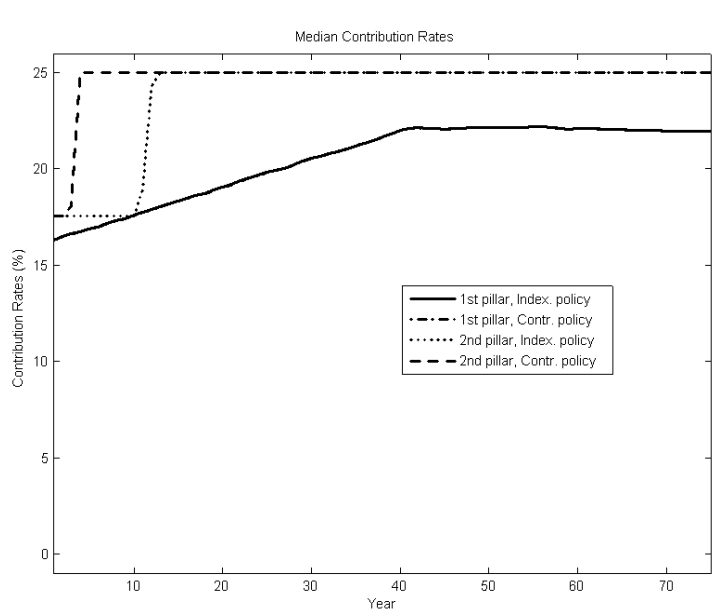

a. Contribution rates

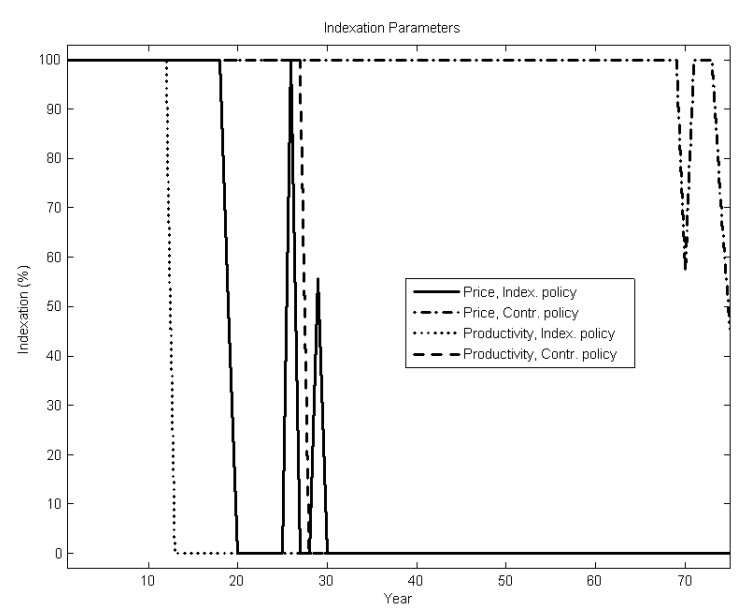

b. Indexation parameters

Figure 6. Alternative policies: median values

We are also interested in comparing welfare under the two policies. When the second-pillar parameters are kept constant over time (i.e., under "no policy"), we obtain social welfare equivalent consumption of the alive generations of $C_{1}^{A}=88.76 \%$ (as computed according to equation (20)). This is higher than social welfare under both an indexation policy $\left(C_{1}^{A}=88.01 \%\right)$ and a contribution policy $\left(C_{1}^{A}=87.52 \%\right)$. One reason is that the aging-induced fall in the funding ratio (as shown in Figure 1b) that would occur under "no policy" is offset through an increase in contributions and/or less indexation. Second, policy interventions introduce additional uncertainty in disposable resources, and therefore consumption. The first line of Table 3 summarises the welfare effect of the alternative policies across all individuals. Social welfare is higher under an indexation policy $\left(C_{1}^{A}=88.01 \%\right)$ than under a contribution policy $\left(C_{1}^{A}=87.52 \%\right)$. Expressed in terms of the certainty equivalent consumption difference, this difference is $\Delta \mathbf{C}_{1}^{A}=-0.56 \%$. One may also wonder whether this finding is confirmed once the welfare of future-born generations is taken into account. The answer is yes, as we find that $\Delta \mathbf{C}_{1}^{T}=-0.48 \%(-0.44 \%)$ using a discount rate of welfare of future generations of $q=4 \%$ (10\%) - see equation (18).

It may also be interesting for policymakers to know what is the share of the alive (voting) population that prefers one policy or the other. The final column of Table 3 reports the average percentage of individuals in the economy that are better off under the contribution policy than under the indexation policy (the measure $D_{1}$ computed according to equation (23)). Of all agents in the economy only $39.69 \%$ prefer the contribution policy. 
Table 3. Welfare consequence of a policy reaction (many shocks over many years)

\begin{tabular}{lcccccc}
\hline \hline & \multicolumn{2}{c}{$\mathbf{C}_{1}^{A}(\%)$} & & \multicolumn{3}{c}{ Welfare comparison (\%) } \\
\cline { 2 - 3 } \cline { 5 - 7 } & Index. & Contr. & & $\Delta \mathbf{C}_{1}^{A}$ or $\Delta \mathbf{C}_{i, 1}^{A}$ & $\Delta \mathbf{C}_{1}^{T}$ or $\Delta \mathbf{C}_{i, 1}^{T}$ & $\mathbf{D}_{1}$ \\
\hline Whole population & $\mathbf{8 8 . 0 1 4 0}$ & $\mathbf{8 7 . 5 2 0 0}$ & & $\mathbf{- 0 . 5 6 1 3}$ & $\mathbf{- 0 . 4 8 2 3}$ & $\mathbf{3 9 . 6 9 2 3}$ \\
Skill group \#1 & 24.9408 & 24.9361 & & -0.0185 & -0.7356 & 50.7261 \\
Skill group \#2 & 37.9377 & 37.9025 & & -0.0927 & -0.4256 & 47.0370 \\
Skill group \#3 & 48.7591 & 48.5584 & & -0.4117 & -0.6150 & 42.5324 \\
Skill group \#4 & 58.5041 & 58.3074 & & -0.3363 & -0.4852 & 40.9440 \\
Skill group \#5 & 67.3886 & 67.1612 & & -0.3374 & -0.3704 & 40.2455 \\
Skill group \#6 & 76.5047 & 76.2383 & & -0.3482 & -0.2960 & 39.9493 \\
Skill group \#7 & 87.4824 & 86.9932 & & -0.5592 & -0.2237 & 39.6874 \\
Skill group \#8 & 103.7908 & 103.1734 & & -0.5948 & -0.2085 & 39.4856 \\
Skill group \#9 & 132.9080 & 132.0207 & & -0.6677 & -0.1448 & 39.2704 \\
Skill group \#10 & 236.9171 & 234.3306 & & -1.0917 & 0.1515 & 39.1090 \\
\hline
\end{tabular}

Note: group \#1 has lowest skill level, while group \#10 has highest skill level

Figure 7 reports the average percentage difference in the CEC (computed according to equation (22)) under the two policies for various cohorts alive at $t=1$ and different skill groups. Most, though not all, cohorts prefer the indexation policy. The indexation policy generates an average welfare gain of around $0.9 \%$ CEC for the middle-aged cohorts and a welfare loss of around $0.5 \%$ for the oldest cohorts. The indexation policy is generally preferred by the working generations as it allows them to share their risks with the retired, while this is not the case under the contribution policy. The retired prefer the contribution policy as this shelters them from the consequences of pension underfunding. Those in the highest income brackets experience the largest welfare effects. This may seem surprising, as these individuals have accumulated more nominal claims, and an indexation policy reduces the indexation parameters more frequently than a contribution policy. This result is driven by the restoration indexation, which allows for indexation above $100 \%$. Indeed, over the entire sample of simulations, the average indexation parameters are higher under indexation policy than under the contribution policy (95.12\% instead of $91.22 \%$ for price indexation, and $81.18 \%$ instead of $70.30 \%$ for productivity indexation).

The welfare difference between the contribution policy and the indexation policy is larger than in the case without shocks (and overturns the ranking there). The reason is that without the shocks, the first adjustment in the instruments was only after forty years, while with shocks, instrument adjustment is often needed in the very short run already (compare Figure 6 with Figure 2). These instrument adjustments which usually go into the direction of reducing consumption resources weigh relatively heavily in the utility computation if they happen early into the simulation run. Hence, the difference in welfare between the two types of policy generally gets more pronounced. The welfare comparison between the two policies also differs across the skill groups (see Table 3 and Figure 7). Excluding the two lowest skill groups, which are on average below or marginally above the franchise and thus indifferent between the two policies, ${ }^{10}$ each skill group has on average a preference for the indexation policy. However, among the highest skill groups we find a relatively larger support for an indexation policy if we look at the generations alive at $t=1$ and for a contribution policy if we also consider the generations born after $t=1$. Only in the highest skill group the welfare comparison $\Delta \mathbf{C}_{10,1}^{T}=0.15 \%$ shows a welfare-improving role for a contribution policy (it is instead $\Delta \mathbf{C}_{10,1}^{T}=-0.07 \%$ if we discount the welfare of future generations at a rate $q=10 \%)$.

\footnotetext{
${ }^{10}$ However, we find a preference for either policy in the few cases where shocks bring these skill classes above the franchise.
} 


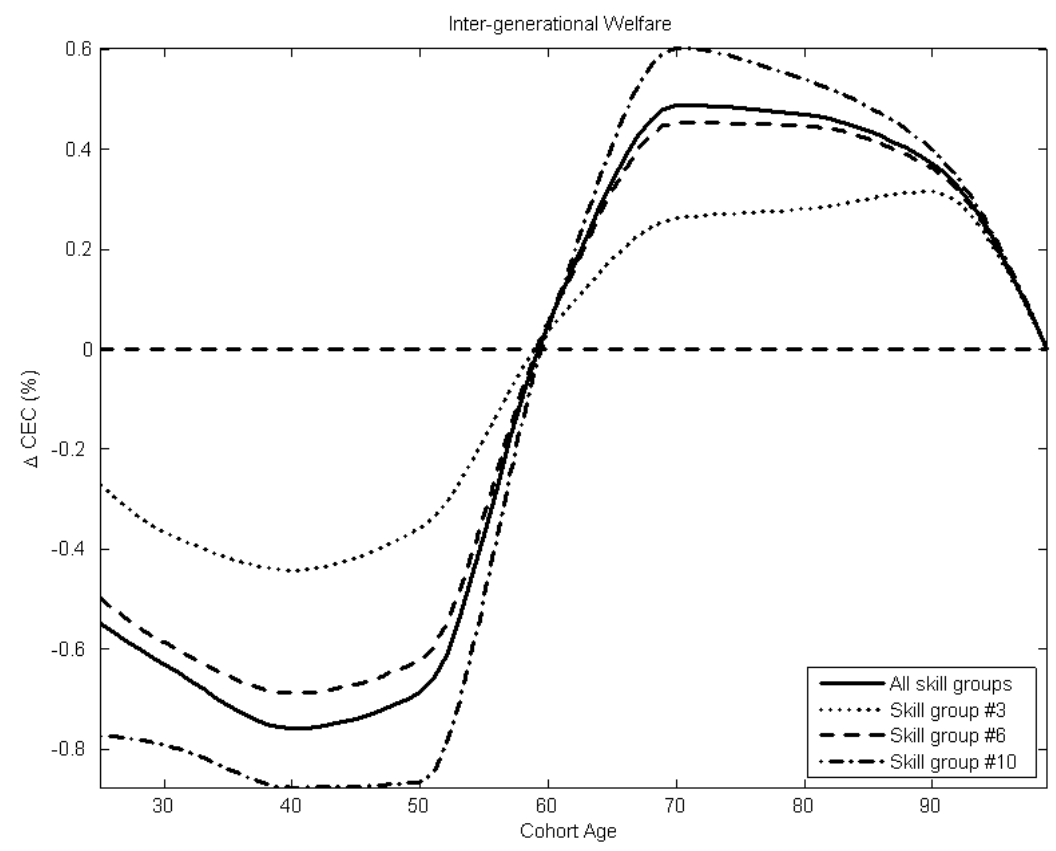

Figure 7. Contribution vs. indexation policy - benchmark

$\triangle C E C>0$ : better-off with the contribution policy

\section{Sensitivity analysis}

Our simulations are based on a variety of assumptions about the economy, in particular on the returns on assets, as well as the institutional features of the social security system. This section explores the robustness of our main results for some of those assumptions. For each scenario we report the number of times the funding ratio falls below the threshold $1+\xi^{l}=105 \%$, welfare $C_{1}^{A}$ under an indexation policy, and the three welfare comparison measures (23)-(25).

\subsection{Growth rates}

First, we explore how our results are affected by the difference between the return on the fund's asset portfolio and the nominal income growth rate. Under our benchmark parameter combination, the average fund portfolio return was $r^{f}=\left(1-z^{e}-z^{h}\right) r_{1}+z^{e} r^{e}+z^{h} r^{h}=4.23 \%$. We consider nominal equity returns of $r^{e}=4 \%$ and $7 \%$, implying average fund returns of $r^{f}=3.50 \%$ and $4.85 \%$ respectively, which translates into a difference with the average income growth $g$ of $r^{f}-g=0.50 \%$ and $1.85 \%$ respectively. In the benchmark scenario, this difference was $1.23 \%$.

The most important (not surprising) consequence of varying the equity return is that the fraction of time the funding ratio is below $105 \%$ falls with the average nominal equity return. Furthermore, welfare increases when average equity returns are higher. However, welfare comparisons are virtually unchanged - on average individuals are still better off under the indexation policy (see Table 4).

\subsection{Dutch shock correlations}

We now use for our stochastic simulation a VAR regression based on Dutch data - see Appendix 7.2.5 for the details. Comparing Tables 6 and 7 in the appendices, we notice a lower volatility of 
inflation, wage and one-year bond shocks for the Netherlands than for the US. In contrast, equity and housing returns are much more volatile. The five variables are also less strongly correlated. As a result, with these new data the funding ratio falls below $105 \%$ during a larger fraction of the time than under the benchmark case (see Table 4).

The two policies generate more similar policy parameters (under the indexation policy on average $\theta_{t}^{S}=18.77 \%, \kappa_{t}=81.52 \%$ and $\iota_{t}=95.47 \%$, while under the contribution policy on average $\theta_{t}^{S}=17.77 \%, \kappa_{t}=72.89 \%$ and $\left.\iota_{t}=92.75 \%\right)$. However, in the simulations all the parameters are also more volatile apart from the contribution rate under contribution policy, whose coefficient of variation actually reduces (it is $60.83 \%$ instead of $63.46 \%$ in the benchmark analysis). Furthermore, the likelihood of restoring missed indexation (linked to either price or productivity) is higher for the contribution policy (missed indexation is restored in $8.14 \%$ of the cases, as opposed to $7.82 \%$ in the benchmark analysis), but it is lower for the indexation policy (9.00\% instead of $9.63 \%$ under the benchmark).

This combination of parameters gives rise to a present value of consumption ${ }^{11}$ that is marginally higher under the contribution policy for all the cohorts aged 45 or more, and ultimately produces a tiny welfare improvement under such policy. In fact, $51.29 \%$ of the population now opt for the contribution policy, and the social welfare improvement with this policy is between $0.11 \%$ and $0.24 \%$ of certain equivalent consumption of an average individual during her remaining lifetime (see Table 4).

Table 4. Variations on the baseline I

\begin{tabular}{lcccccccc}
\hline \hline & \multicolumn{2}{c}{ Prob. $\mathbf{F}_{t}<\mathbf{1 0 5} \%$} & & \multicolumn{2}{c}{$\mathbf{C}_{1}^{A}(\%)$} & & \multicolumn{2}{c}{ Welfare comparison (\%) } \\
\cline { 2 - 3 } & Index. & Contr. & & Index. & & $\Delta \mathbf{C}_{1}^{A}$ & $\Delta \mathbf{C}_{1}^{T}$ & $\mathbf{D}_{1}$ \\
\hline Benchmark & $\mathbf{2 0 . 7 1 4 7}$ & $\mathbf{2 1 . 8 1 8 7}$ & & $\mathbf{8 8 . 0 1 4 0}$ & & $\mathbf{- 0 . 5 6 1 3}$ & $\mathbf{- 0 . 4 8 2 3}$ & $\mathbf{3 9 . 6 9 2 3}$ \\
$r^{e}=4 \%$ & 22.2107 & 23.3827 & & 82.9388 & & -0.9171 & -0.3320 & 39.9639 \\
$r^{e}=7 \%$ & 19.3680 & 20.1693 & & 92.5923 & & -0.4671 & -0.2197 & 41.8710 \\
Dutch correlations & 23.3920 & 24.0680 & & 85.1668 & & 0.1093 & 0.2357 & 51.2939 \\
\hline
\end{tabular}

The welfare comparison by cohorts (Figure 8) indicates a pattern similar to that under the benchmark, although now fewer cohorts prefer the indexation policy. The preference for the contribution policy is relatively larger among the low-skilled groups. In particular, $58.56 \%$ of the individuals in the third group would be in favour of such policy.

\footnotetext{
${ }^{11}$ Computed discounting future consumption flows at a fixed discount rate, equal to the average bond interest rate.
} 


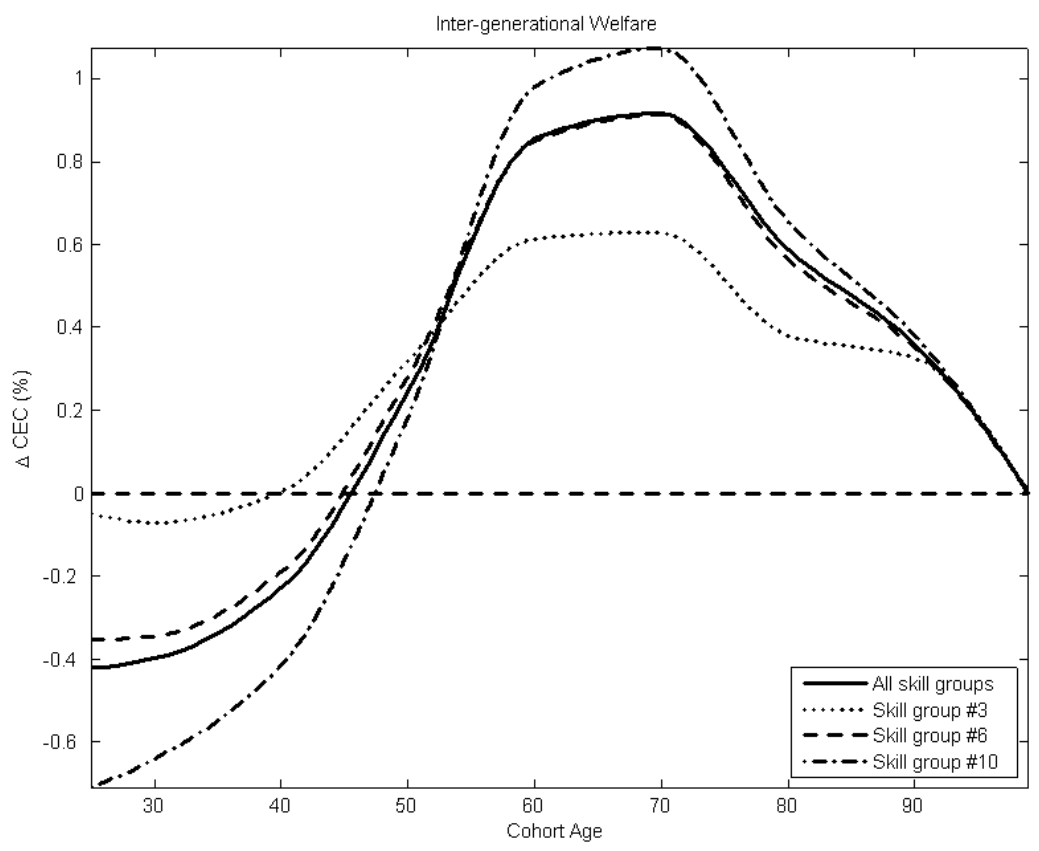

Figure 8. Contribution vs. indexation policy - Dutch correlations

$\triangle C E C>0$ : better-off with the contribution policy

\subsection{Institutional features}

Dutch pension fund regulation has evolved substantially in recent years. First, while in the past benefits were usually based on the final wage, now in most cases they are based on the average wage, as has been assumed so far. Second, while liabilities used to be discounted at a fixed interest rate (usually of 4\%), the introduction of new international accounting standards require liabilities to be discounted at the market yield curve. ${ }^{12}$ Here we explore the consequences of these changes. We also investigate the consequences of parametric changes in the system, in particular, variations in the restoration periods, the retirement age and the size of the second pillar relative to that of the first pillar.

\subsubsection{A fixed discount rate for liabilities}

The yield curve varies substantially from year to year. This has profound effects on the behaviour of the funding ratio, because the yield curve is used to discount the complete stream of future pension benefits. The Dutch pension sector often complains about the implied instability in the funding ratio, which forces them to implement undesirable and often unnecessary policy adjustments. To assess whether these complaints are warranted we rerun our simulations assuming that the yield curve used to discount pension liabilities is fixed at its average profile $\left\{r_{k}\right\}_{k=1}^{D}$ estimated in Appendix 7.2.4 and shown in Figure 9.

Table 5 shows that with a fixed discounting profile, either policy is more effective in reducing the number of times in which the funding ratio falls below $105 \%$, from around $20 \%$ of the benchmark case to around $6 \%$. The coefficient of variation of the funding ratio also reduces sizably, from around $19 \%$ to around $12 \%$. Under this scenario, adjustments in the instrument parameters are

\footnotetext{
${ }^{12}$ Actually, discounting is against the spot swap curve. However, a sufficiently liquid market for swaps has not existed for long enough to estimate a model for the swap curve.
} 
less frequently changed than under the benchmark: in $21.08 \%$ of the cases (instead of $28.82 \%$ ) under the indexation policy and in just $8.24 \%$ of the cases (instead of $13.91 \%$ ) under the contribution policy. As a result, the volatility of lifetime consumption is smaller under the contribution policy. For this reason the three welfare measures all suggest a moderate welfare improvement under the contribution policy. The analysis of alternative methods of discounting liabilities will be a topic for future research.

\subsubsection{Benefits based on final wage}

We consider now the case in which the benefit of a cohort entering retirement at age $R+1$ is based on the final rather than the average wage, a situation that prevailed in the Netherlands before 2004. As before, benefits are based on (9), but with nominal rights now given by

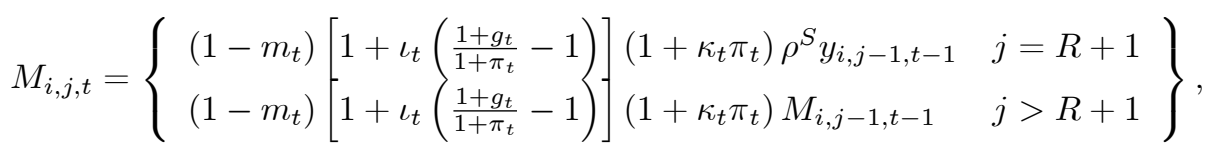

which replaces equation (10). Here we set $\rho^{S}=0.365$ to generate the same average replacement rate as in the benchmark analysis. Notice that under this alternative benefits are more heavily exposed to shocks in income growth than under the benchmark. As a result, social welfare is much lower than in the benchmark case (under indexation policy, $C_{1}^{A}=78.41 \%$ instead of $88.01 \%$ in the benchmark case). Adjustments in indexation no longer affect workers and, hence, risk-sharing between young and old via this channel is no longer possible.

We see from Table 5 that while a lower fraction of individuals now support a contribution policy $(32.81 \%)$, the difference in welfare between the two policies, as measured by the difference in certainty equivalent consumption, is smaller.

\subsubsection{Varying the restoration period in the short-term plan}

We consider two alternative values for $K^{S}$, namely a three-year and a ten-year restoration period. The results are reported in Table 5. There are modest changes with respect to the benchmark case. A (not surprising) effect is that an increase in the restoration period raises the percentage of time the funding ratio falls below the $105 \%$ threshold (no more than $21 \%$ of the time when $K^{S}=3$ versus no more than $24 \%$ of the time when $K^{S}=10$ ). Under both alternatives, there is again a large majority in favour of the indexation policy. An increase in the restoration period slightly raises the relative desirability of the contribution policy as measured by the majority in favour of it, which rises from $39 \%$ when $K^{S}=3$ to $44 \%$ when $K^{S}=10$, and also as measured in terms of the difference in certainty-equivalent consumption of the alive generations, which rises from $-0.47 \%$ when $K^{S}=3$ to $-0.39 \%$ when $K^{S}=10$. Under a contribution policy a larger share of the restoration burden can be shifted on future entrants into the labour market when the restoration period is prolonged. This ameliorates the relative disadvantage to the contribution policy.

\subsubsection{Varying the retirement age}

Increasing life expectancy has prompted a number of countries to raise, sometimes gradually, the retirement age while keeping the replacement rate unchanged. The retirement age affects not only the individual life-cycle consumption profile, but also the components of the funding ratio (equations (11) and (12)). An increase in the retirement age implies an increase in the number of people contributing to the pension fund and a reduction in the number of people receiving benefits. We consider two alternative values for the retirement age, namely retirement two years earlier than 
the benchmark $(R=38)$ and two years later than the benchmark $(R=42)$. In the new scenarios, the model endogenously sets different contribution rates: for the first pillar the initial values are $\theta_{1}^{F}=19.59 \%$ and $13.62 \%$ if $R=38$ and $R=42$, respectively. For the second pillar, the initial value are $\theta_{1}^{S}=21.10 \%$ and $14.56 \%$, respectively. In the benchmark case of Section 4.3 the initial contribution rates are instead set to $\theta_{1}^{F}=16.42 \%$ and $\theta_{1}^{S}=17.58 \%$. To preserve the average second-pillar replacement rate of the benchmark analysis (37.60\% of the final wage), we also set the accrual rate to $\mu=1.85 \%$ if $R=38$ and $\mu=1.664 \%$ if $R=42$. The likelihood of underfunding falls as the retirement age is increased. However, in terms of the welfare ranking we find no relevant change (Table 5). A large majority of the individuals remain in favour of the indexation policy. A reduction in the retirement age slightly reduces the relative preference for the indexation policy, because the scope for escaping (through retirement) part of the burden of keeping the buffer stable is increased under the contribution policy.

\subsubsection{Relative size of the two pillars}

In our benchmark calibration, the expected replacement rates of final income from the first and second pillars are respectively $30.40 \%$ and $37.60 \%$. This roughly corresponds to the current situation in the Netherlands. However, it seems reasonable to believe that the second pillar will become relatively more important in the future as the number of people participating in a pension fund rises and the political support for a PAYG pension pillar in which current workers pay for current retirees shrinks. Likely the first pillar will more and more become a provision to merely keep retirees out of poverty.

We consider the case of $\rho^{F}=11.19 \%$ and $\mu=2.234 \%$, while keeping the remaining parameters at their benchmark values. This new calibration generates for the average-income individual an expected replacement rate of the final wage of $20 \%$ and $48 \%$, respectively, for the first and second pension pillars. Hence the total replacement rate provided by the social security system is unchanged on average (68\%), but the second pillar has become larger relative to the first pillar. The certainty-equivalent consumption differences, $\Delta \mathbf{C}_{1}^{A}$ and $\Delta \mathbf{C}_{1}^{T}$, are closer to zero, and the fraction of those in favour of the contribution policy has become slightly larger. All the indicators, however, continue showing a preference for the indexation policy. Importantly, social welfare is larger under this scenario than in the benchmark case $\left(\mathbf{C}_{1}^{A}=90.47 \%\right.$ instead of $\left.88.01 \%\right)$ or any of the other cases with changes in the institutional structure. A funded social security system is indeed welfare improving in this economy. In the extreme situation with only the PAYG system (paying the same average replacement rate as in the benchmark), social welfare would drop to $\mathbf{C}_{1}^{A}=68.13 \%$.

Table 5. Variations on the baseline II

\begin{tabular}{lcclccccc}
\hline \hline & \multicolumn{2}{c}{ Prob. $\mathbf{F}_{t}<\mathbf{1 0 5} \%$} & & \multicolumn{2}{c}{$\mathbf{C}_{1}^{A}(\%)$} & & \multicolumn{3}{c}{ Welfare comparison (\%) } \\
\cline { 2 - 3 } & Index. & Contr. & & Index. & & $\Delta \mathbf{C}_{1}^{A}$ & $\Delta \mathbf{C}_{1}^{T}$ & $\mathbf{D}_{1}$ \\
\hline Benchmark & $\mathbf{2 0 . 7 1 4 7}$ & $\mathbf{2 1 . 8 1 8 7}$ & & $\mathbf{8 8 . 0 1 4 0}$ & & $\mathbf{- 0 . 5 6 1 3}$ & $\mathbf{- 0 . 4 8 2 3}$ & $\mathbf{3 9 . 6 9 2 3}$ \\
Fixed discounting & 6.3427 & 7.5400 & & 86.5875 & & 0.6777 & 0.4429 & 65.9459 \\
Final wage benefits & 22.7173 & 22.9333 & & 78.4100 & & -0.4836 & -0.0004 & 32.8114 \\
Rest. period: $K^{S}=3$ & 21.0120 & 21.0920 & & 87.9063 & & -0.4697 & -0.5405 & 39.3408 \\
Rest. period: $K^{S}=10$ & 22.7493 & 23.7453 & & 88.0402 & & -0.3865 & -0.5299 & 43.6697 \\
Retirement age: age 63 & 21.6693 & 23.0613 & & 89.0188 & & -0.3308 & -0.2949 & 42.8349 \\
Retirement age: age 67 & 19.7507 & 20.4613 & & 87.0795 & & -0.5279 & -0.3757 & 39.7242 \\
Size of the two pillars & 22.3907 & 23.6560 & & 90.4717 & & -0.4660 & -0.1093 & 40.8316 \\
\hline
\end{tabular}




\section{Conclusions and directions for future research}

In this paper we have explored the inter-generational and intra-generational welfare implications of different pension buffer policies in the context of an OLG model of a small-open economy. The economy was subjected to demographic, financial and economic shocks estimated for the US, while our two-pillar pension system was modelled after the Dutch system. Under a contribution policy, the contribution rate was always adjusted first, followed by the indexation rates and a cut in nominal pension rights (in the case of underfunding), while under an indexation policy indexation to productivity and prices were always reduced first, followed by an increase in the contribution rate and a reduction in nominal rights. In almost all variants we considered, the indexation policy was preferred by a (large) majority, the reason being that pension risks (the risks associated with maintaining a stable pension buffer) can be spread over all generations when indexation rates are adjusted, while the burden of changes in the contribution rate are borne entirely by the workers. We have also quantified the welfare differences between the two policies for different cohorts and skill groups, showing that these differences are non-negligible when expressed in differences in certainty equivalent consumption over the remaining lifetime. An important further result of our simulations is that the funding ratios are highly volatile, while most of this volatility is caused by the movements in the yield curve.

Future research will extend the work in this paper into several directions. In particular we plan to focus on three aspects. First, we will explore the welfare implications of age-dependent indexation. Since younger generations have accumulated fewer nominal assets, a reduction in indexation affects the purchasing power of their accumulated claims to a smaller extent than that of the old, while moreover the young have more time left for the expected restoration of their purchasing power. This suggests that it may be beneficial to differentiate changes in indexation by age. Second, we intend to introduce endogenous labour supply into the model, in order to take account of the potential losses arising through the labour market distortions caused by changes in pension contribution rates. Third, we want to include the current framework into a general equilibrium setting, in which wages, interest rates and equity returns are endogenously determined. A further extension concerns the inclusion of a demand side of the economy, which may help us to asses whether it might be optimal to have pro-cyclical pension contribution rates that dampen fluctuations in disposable income.

\section{Appendix}

\subsection{Detailed rules for adjustment of policy parameters}

The adjustment policy works as follows. In case no restoration plan from an earlier period is still active in $t$ :

1. If $F_{t}<1+\xi^{l}$, a short-term restoration plan is started that after $K^{s}$ years in the absence of shocks brings back along a linear growth path the funding ratio at $1+\xi^{l}$. Hence, the sequence of policy parameter combinations $\left(\theta_{t+1}^{S}, \kappa_{t+1}, \iota_{t+1}\right), \ldots,\left(\theta_{t+K^{s}}^{S}, \kappa_{t+K^{s}}, \iota_{t+K^{s}}\right)$ is set at period $t$ such that the funding ratios $\widetilde{F}_{t+1}, \widetilde{F}_{t+2}, \ldots, \widetilde{F}_{t+K^{s}}$ projected from $F_{t}$ in the absence of further shocks hit the target funding ratios $\bar{F}_{t+\tau}=F_{t}+\left[\left(1+\xi^{l}\right)-F_{t}\right] \frac{\tau}{K^{s}}$ for years $\tau=1, \ldots, K^{s}$. For every period $t+\tau$ along the restoration path, the combination of parameters $\left(\theta_{t+\tau}^{S}, \kappa_{t+\tau}, \iota_{t+\tau}\right)$ is set according to either an indexation policy or a contribution policy (see below). If after applying all these measures the funding ratio still falls short 
of $\bar{F}_{t+\tau}$, we set $\theta_{t+\tau}^{S}=\theta^{S, \max }, \kappa_{t+\tau}=\iota_{t+\tau}=0$ and apply a reduction in nominal rights $m_{t+\tau}>0$ such that $\widetilde{F}_{t+\tau}=\bar{F}_{t+\tau}$.

2. If $1+\xi^{l} \leq F_{t}<1+\xi^{m}$, a long-term restoration plan is started that after $K^{l}$ years in the absence of shocks brings back along a linear growth path the funding ratio at $1+\xi^{m}$. Hence, the sequence of policy parameter combinations $\left(\theta_{t+1}^{S}, \kappa_{t+1}, \iota_{t+1}\right), \ldots,\left(\theta_{t+K^{l}}^{S}, \kappa_{t+K^{l}}, \iota_{t+K^{l}}\right)$ is set at period $t$ such that the funding ratios $\widetilde{F}_{t+1}, \widetilde{F}_{t+2}, \ldots, \widetilde{F}_{t+K^{l}}$ projected from $F_{t}$ in the absence of further shocks hit the target funding ratios $\bar{F}_{t+\tau}=F_{t}+\left[\left(1+\xi^{m}\right)-F_{t}\right] \frac{\tau}{K^{l}}$ for years $\tau=1, \ldots, K^{l}$. For every period $t+\tau$ along the restoration path, the combination of parameters $\left(\theta_{t+\tau}^{S}, \kappa_{t+\tau}, \iota_{t+\tau}\right)$ is set according to either an indexation policy or a contribution policy (see below). If after applying all these measures the funding ratio still falls short of $\bar{F}_{t+\tau}$, we set $\theta_{t+\tau}^{S}=\theta^{S, \max }, \kappa_{t+\tau}=\iota_{t+\tau}=0$, but we apply no reduction in nominal rights.

3. If $1+\xi^{m} \leq F_{t}<1+\xi^{u}$, there are two cases.

(a) In the absence of any missed nomimal rights (see below), the next-year policy parameters are set to $\theta_{t+1}^{S}=\theta_{t}^{S}$ and $\kappa_{t+1}=\iota_{t+1}=1$.

(b) In the presence of missed (unrestored) nominal rights, the next-year policy parameters are set to $\theta_{t+1}^{S}=\theta_{t}^{S}$ and $\kappa_{t+1}=\iota_{t+1}=0$.

4. If $F_{t} \geq 1+\xi^{u}, m_{t+1}$ is set to restore any missed nominal rights (as described below) to the extent that the funding ratio does not fall below the target ratio $1+\xi^{u} \cdot{ }^{13}$ If after restoring possible missed nominal rights still $\widetilde{F}_{t+1}>1+\xi^{u}$, then further adjustment to the policy parameters is made according to either an indexation policy or a contribution policy (as described below). If after applying these measures still $\widetilde{F}_{t+1}>1+\xi^{u}$, then price indexation is raised by an extra amount $\hat{\kappa}_{t+1}>0$ such that over a period of three years along a linear path in the absence of shocks the funding ratio is back at $1+\xi^{u}$.

In case a long-term restoration plan from an earlier period is still active in $t$ :

1. If $F_{t}<1+\xi^{l}$, the long-term restoration plan is cancelled and the policymaker follows the above policy under "no restoration plan" from an earlier period still active in $t$. That is, it sets up a short-run restoration plan as determined above.

2. If $1+\xi^{l} \leq F_{t}<1+\xi^{m}$, there are two cases:

(a) If $F_{t}<\bar{F}_{t}$, either an indexation policy or a contribution policy is used to produce a modified long-term restoration plan in exactly the same way as described above, but only over the remaining years of the original plan. If this implies that the next period's funding ratio still falls below $\bar{F}_{t+1}$, the policy parameter combination remains at $\theta_{t+1}^{S}=\theta^{S, \max }, \kappa_{t+1}=\iota_{t+1}=0$ and no further action is undertaken.

(b) If $\bar{F}_{t} \leq F_{t}<1+\xi^{m}$, the policy parameters are those prescribed by the long-term restoration plan.

3. If $1+\xi^{m} \leq F_{t}<1+\xi^{u}$, then the above policy under "no restoration plan" from an earlier period still active in $t$ is followed.

\footnotetext{
${ }^{13}$ Dutch pension law says that a pension fund is not allowed to reduce contribution rates until any earlier reduction in nominal rights is undone.
} 
4. If $F_{t} \geq 1+\xi^{u}$, then the above policy under "no restoration plan" from an earlier period still active in $t$ is followed.

In case a short-term restoration plan from an earlier period is still active in $t$ :

1. If $F_{t}<1+\xi^{l}$, there are two cases:

(a) If $F_{t}<\bar{F}_{t}$, either an indexation policy or a contribution policy is used to produce a modified short-term restoration plan exactly in the same way as above, but only over the remaining years of the original plan. If after applying these measures next period's funding ratio still falls below $\bar{F}_{t+1}$, the policymaker sets $\theta_{t+1}^{S}=\theta^{S, \max }, \kappa_{t+1}=\iota_{t+1}=0$ and $m_{t+1}>0$ such that in the absence of shocks $\widetilde{F}_{t+1}=\bar{F}_{t+1}$.

(b) If $\bar{F}_{t} \leq F_{t}<1+\xi^{l}$, the policy parameters are those prescribed by the existing short-term restoration plan.

2. If $1+\xi^{l} \leq F_{t}<1+\xi^{m}$, then the above policy under no restoration plan from an earlier period still active in $t$ is followed. That is, a long-term restoration plan is set up in the way described above.

3. If $1+\xi^{m} \leq F_{t}<1+\xi^{u}$, then the above policy under no restoration plan from an earlier period still active in $t$ is followed.

4. If $F_{t} \geq 1+\xi^{u}$, then the above policy under no restoration plan from an earlier period still active in $t$ is followed.

The indexation and contribution policies are defined as follows:

- Indexation policy:

1. If a short-term restoration plan is started in period $t$, productivity indexation $\iota_{t+1}$ is reduced up to a minimum level of zero to hit the prescribed target path. If this is not enough, price indexation $\kappa_{t+1}$ is reduced up to a minimum level of zero. If this is still not enough, the contribution rate $\theta_{t+1}^{S}$ is increased up to a maximum of $\theta^{S, \max }$. Analogously, when an existing short-term plan has to be modified.

2. If a long-term restoration plan is started in period $t$, productivity indexation $\iota_{t+1}$ is reduced up to a minimum level of zero to hit the prescribed target path. If this is not enough, price indexation $\kappa_{t+1}$ is reduced up to a minimum level of zero. If this is still not enough, the contribution rate $\theta_{t+1}^{S}$ is increased up to a maximum of $\theta^{S, \text { max }}$. Analogously, when an existing long-term plan has to be modified.

3. If $F_{t} \geq 1+\xi^{u}$, after restoring the missed nominal rights (as described below), missed price indexation is restored (as described below) to attain $1+\xi^{u}$. If this is not enough, missed productivity indexation is restored (as described below). If this is still not enough, the contribution rate $\theta_{t+1}^{S}$ is lowered up to a minimum of 0 .

and 
1. If a short-term restoration plan is started in period $t$, the contribution rate $\theta_{t+1}^{S}$ is raised up to a maximum of $\theta^{S, \max }$ to hit the prescribed target path. If this is not enough, productivity indexation $\iota_{t+1}$ is reduced up to a minimum level of zero. If this is still not enough, price indexation $\kappa_{t+1}$ is reduced up to a minimum level of zero. Analogously, when an existing short-term plan has to be modified.

2. If a long-term restoration plan is started in period $t$, the contribution rate $\theta_{t+1}^{S}$ is raised up to a maximum of $\theta^{S, \max }$ to hit the prescribed target path. If this is not enough, productivity indexation $\iota_{t+1}$ is reduced up to a minimum level of zero. If this is still not enough, price indexation $\kappa_{t+1}$ is reduced up to a minimum level of zero. Analogously, when an existing long-term plan has to be modified.

3. If $F_{t} \geq 1+\xi^{u}$, after restoring the missed nominal rights (as described below), the contribution rate $\theta_{t+1}^{S}$ is reduced up to a minimum of 0 to attain $1+\xi^{u}$. If this is not enough, missed price indexation is restored (as described below). If this is still not enough, missed productivity indexation is restored (as described below).

We restore missed price and productivity indexation and missed nominal rights as follows. Let us take the case of price indexation. For this case, we define two processes, an "actual" process (tracking the actual indexation that has been given, where $\pi$ is long-run average inflation),

$$
p_{t}^{\kappa, a}=\left(1+\kappa_{t} \pi\right) p_{t-1}^{\kappa, a}
$$

and a "shadow" process that corresponds to always having full indexation:

$$
p_{t}^{\kappa, s}=(1+\pi) p_{t-1}^{\kappa, s} .
$$

We set the processes equal to unity at $t=1$ ( $D$ periods into the simulation run): $p_{1}^{\kappa, a}=p_{1}^{\kappa, s}=1$.

Suppose that in period $t$, the funding ratio exceeds $1+\xi^{u}$. Then, indexation for the next period will at least be equal to full indexation: $\kappa_{t+1} \geq 1$. In case $p_{t}^{\kappa, a}<p_{t}^{\kappa, s}$, the indexation in the next period will be set at most so high that the missed indexation is restored in expected terms. That is, $\kappa_{t+1}$ will be set at most such that $p_{t+1}^{\kappa, a}=p_{t+1}^{\kappa, s}$, which is equivalent to $\left(1+\kappa_{t+1} \pi\right) p_{t}^{\kappa, a}=(1+\pi) p_{t}^{\kappa, s}$, which in turn is solved as:

$$
\kappa_{t+1}^{r e s t o r e}=\frac{1}{\pi}\left(\frac{p_{t}^{\kappa, s}}{p_{t}^{\kappa, a}}-1\right)+\frac{p_{t}^{\kappa, s}}{p_{t}^{\kappa, a}} .
$$

Finally, we define $\kappa_{t+1}^{u}$ as the indexation rate that brings the funding ratio to $1+\xi^{u}$ next year in the absence of further shocks. Actual indexation $\kappa_{t+1}$ will be set at:

$$
\kappa_{t+1}=\min \left\{\max \left\{1, \kappa_{t+1}^{u}\right\}, \kappa_{t+1}^{\text {restore }}\right\} .
$$

The processes continue further according to (27) and (28) until the end of the simulation run.

For missed productivity indexation, we similarly define the "actual", respectively "shadow", processes:

$$
\begin{aligned}
& p_{t}^{\iota, a}=\left(1+\iota_{t}\left(\frac{1+g}{1+\pi}-1\right)\right) p_{t-1}^{\iota, a} \\
& p_{t}^{\iota, s}=\left(1+\left(\frac{1+g}{1+\pi}-1\right)\right) p_{t-1}^{\iota, s}
\end{aligned}
$$


where $p_{1}^{\iota, a}=p_{1}^{\iota, s}=1$. Restoration of indexation is completely similar to that in the case of price indexation.

Finally, for reductions in nominal rights (captured by $m_{t}>0$ ), we define the "actual", respectively "shadow", processes

$$
\begin{aligned}
p_{t}^{m, a} & =\left(1-m_{t}\right) p_{t-1}^{m, a}, \\
p_{t}^{m, s} & =p_{t-1}^{m, s} .
\end{aligned}
$$

where $p_{1}^{m, a}=p_{1}^{m, s}=1$. Again, if at some moment $t$, we have $p_{t}^{m, a}<p_{t}^{m, s}$ and the funding ratio exceeds $1+\xi^{u}$, missed nominal rights can be given back up to a maximum level such that $p_{t+1}^{m, a}=p_{t+1}^{m, s}$. The exact formula for the restoration of missed nominal rights is

$$
m_{t+1}=\max \left\{\min \left\{0,1-\frac{\widetilde{F}_{t+1}}{1+\xi^{u}}\right\}, \min \left\{0,1-\frac{p_{t}^{m, s}}{p_{t}^{m, a}}\right\}\right\}
$$

where $\widetilde{F}_{t+1}$ is the projection at time $t+1$ of the funding ratio in the absence of further shocks. To see the first argument of this expression, notice that if $m_{t+1}=1-\frac{\widetilde{F}_{t+1}}{1+\xi^{u}}$, all nominal rights are multiplied by the factor $\frac{\widetilde{F}_{t+1}}{1+\xi^{u}}$. Hence, all future pension benefits are multiplied by this same factor and, then, total liabilities are multiplied by this same factor, implying that the funding ratio becomes $1+\xi^{u}$.

\subsection{Details on the calibration}

\subsubsection{Growth rate of the newborn cohort}

For the number of births in the US between 1985 and 2005 (source: HMD, 2009), we estimate the model:

$$
\begin{gathered}
n_{t}=n+\epsilon_{t}^{n}, \\
\epsilon_{t}^{n}=\varphi \epsilon_{t-1}^{n}+\eta_{t}^{n}, \quad \eta_{t}^{n \sim} N\left(0, \sigma_{n}^{2}\right) .
\end{gathered}
$$

This yields $n=0.0047362, \varphi=0.4543931$ (standard error 0.2223041 ) and $\sigma_{n}=0.0132662$ (standard error 0.0017105).

\subsubsection{Survival probabilities}

Our simulations require cohort life tables, which are incomplete for recent cohorts. Using easily available period life tables, however, leads to an over-estimate of mortality because of the well documented downward trend in mortality. To correctly estimate mortality, we follow the LeeCarter model (Lee and Carter, 1992) and collect from the HMD (2009) US period life tables from 1950 to 2005. These contain the total population on a year-by-year basis from ages 0 to 110 . We call $\psi_{j, t}^{p}$ the probability of being alive in year $t$ for individuals aged $j$, conditional on having been alive at age $j-1$. To distinguish the trend from fluctuations, we estimate with singular value decomposition the parameters of the Lee-Carter model:

$$
\ln \left(1-\psi_{j, t}^{p}\right)=\alpha_{j}+\tau_{j} \chi_{t}+\eta_{t}^{\psi},
$$

where $\alpha_{j}$ and $\tau_{j}$ are age-varying parameters, $\chi_{t}$ is a time-varying vector and $\eta_{t}^{\psi}$ is a random disturbance distributed as $N\left(0, \widetilde{\sigma}_{\psi}^{2}\right)$. Lee and Carter (1992) point out that the parameterization is not unique. Therefore, we choose the one fulfilling their suggested restrictions: 


$$
\left\{\begin{array}{l}
\sum_{t=1}^{T} \chi_{t}=0 \\
\sum_{j=1}^{D} \tau_{j}=1
\end{array}\right\}
$$

where $t=1, . ., T$ indicates the sample period. With these restrictions the estimated value for $\alpha_{j}$ will be the average probability over the sample that someone dies at age $j$, when having survived up to age $j-1 .{ }^{14}$ Consistently with the existing literature we assume that the mortality index $\chi_{t}$ evolves as a random walk with drift $\chi$ :

$$
\chi_{t}=\chi_{t-1}+\chi+\epsilon_{t}^{\psi}
$$

with $\epsilon_{t}^{\psi \sim} N\left(0, \sigma_{\psi}^{2}\right)$. With our data we estimate $\hat{\chi}=-1.2595$ and $\hat{\sigma}_{\psi}=0.0266$, thereby implying a trend fall in the probability of dying at any age $j$, conditional on having survived up to age $j-1$. In the simulations we assume that $\hat{\chi}=0$ after year $t=40$, that is, there is no further population ageing after 40 years. We make this assumption to avoid dealing with very large contribution rates in the first- and second-pillar systems and on the assumption that the ageing process cannot continue forever.

From the period life table estimates and the trend of the mortality index we calculate the cohort life tables as follows:

$$
\begin{aligned}
\ln \left(1-\psi_{j, t-j+1}\right) & =\hat{\alpha}_{j}+\hat{\tau}_{j}\left(\hat{\chi}_{t-j+1}+j \hat{\chi}\right) \\
& =\hat{\alpha}_{j}+\hat{\tau}_{j} \hat{\chi}_{t+1}
\end{aligned}
$$

where $t-j+1$ is the year of birth of the cohort. Thus $\psi_{j, t-j+1}$ indicates the (estimated) probability of being alive at age $j$ (end of period $t$ ) for the cohort of individuals born at the beginning of year $t-j+1$, conditional on them being alive at age $j-1$. In our model, the survival probabilities $\left\{\psi_{j, D}\right\}_{j=1}^{D}$ of the cohort born in year $t=0$ are set equal to those of the actual cohort of individuals born in 1950 .

The survival probability for the cohort born in the following year $t-j+2$ evolves according to:

$$
\begin{aligned}
\ln \left(1-\psi_{j, t-j+2}\right) & =\hat{\alpha}_{j}+\hat{\tau}_{j}\left(\hat{\chi}_{t-j+2}+j \hat{\chi}\right) \\
& =\alpha_{j}+\hat{\tau}_{j}\left(\hat{\chi}_{t-j+1}+j \hat{\chi}+\hat{\chi}\right) \\
& =\alpha_{j}+\hat{\tau}_{j}\left(\hat{\chi}_{t+1}+\hat{\chi}\right) \\
& =\ln \left(1-\psi_{j, t-j+1}\right)+\hat{\tau}_{j} \hat{\chi}
\end{aligned}
$$

\subsubsection{Economic shocks}

We assume that the shocks to our five economic and financial variables (the inflation rate, the nominal wage growth rate, the one-year bond return, the equity return and the housing return) evolve according to a $\operatorname{VAR}(1)$ process. The underlying data are the following time series: for the inflation rate, the US Consumer Price Index; for the nominal income growth rate, the US hourly

\footnotetext{
${ }^{14}$ Notice that $\frac{1}{T} \sum_{t=1}^{T} \ln \left(1-\psi_{j, t}^{p}\right)=\frac{1}{T} \sum_{t=1}^{T}\left(\alpha_{j}+\tau_{j} \chi_{t}+\eta_{t}^{\psi}\right)=\alpha_{j}+\tau_{j}\left(\frac{1}{T} \sum_{t=1}^{T} \chi_{t}\right)+\left(\frac{1}{T} \sum_{t=1}^{T} \eta_{t}^{\psi}\right)=\alpha_{j}+\left(\frac{1}{T} \sum_{t=1}^{T} \eta_{t}^{\psi}\right)$ $=\hat{\alpha}_{j}+\left(\frac{1}{T} \sum_{t=1}^{T} \hat{\eta}_{t}^{\psi}\right)=\hat{\alpha}_{j}$, where $\hat{\alpha}_{j}$ is the estimate of $\alpha_{j}$ and $\hat{\eta}_{t}^{\psi}$ is the regression residual. The last equality is obtained by using that the sum of the residuals is zero.
} 
wage (source for both series: OECD, 2009); for the one-year bond return, the US end-of-year public debt yield at maturity one year (source: Federal Reserve, 2009); for the equity return, the MSCI US equity index (source: Datastream, 2009); for the housing return, the OFHEO house price index (now FHFA index, source: Federal Housing Finance Agency, FHFA, 2009). All the series are annual over the period 1976-2005 (30 observations). For each series we take the deviations from the historical average.

Our shocks consist of a deterministic component, which is a linear combination of previousyear shocks, and a purely random component, given by realizations from i.i.d. innovations. The estimation of the deterministic component is shown in panel a of Table 6 . It is worth pointing out that no variable in the specification of the equity return is significantly different from zero; indeed, a Wald chi-squared test does not reject the hypothesis that equity returns follow a purely random (white noise) process.

Table 6. $\operatorname{VAR}(1)$ regression

a. Deterministic coefficient estimates (matrix B in (17))

\begin{tabular}{cccccc}
\hline \hline Variable & Inflation & Wage & Bond & Equity & Housing \\
\hline Inflation (-1) & $0.7864^{* * *}$ & $0.3060^{* *}$ & $0.3694^{* *}$ & -1.5158 & $-0.8204^{* * *}$ \\
& $(0.1747)$ & $(0.1192)$ & $(0.1840)$ & $(2.1683)$ & $(0.2660)$ \\
Wage (-1) & 0.0185 & $0.6609^{* * *}$ & -0.0786 & 0.3825 & $1.0658^{* * *}$ \\
& $(0.1930)$ & $(0.1317)$ & $(0.2033)$ & $(2.3953)$ & $(0.2938)$ \\
Bond (-1) & -0.0555 & $-0.1661^{* *}$ & $0.6857^{* * *}$ & 1.3535 & -0.2609 \\
& $(0.1104)$ & $(0.0753)$ & $(0.1163)$ & $(1.3700)$ & $(0.1681)$ \\
Equity (-1) & 0.0094 & 0.0125 & 0.0252 & -0.0247 & 0.0119 \\
& $(0.0148)$ & $(0.0101)$ & $(0.01554)$ & $(0.1831)$ & $(0.0225)$ \\
Housing (-1) & $0.2903^{* * *}$ & $0.0957^{*}$ & $0.1533^{* *}$ & -1.0446 & $0.6839^{* * *}$ \\
& $(0.0779)$ & $(0.0531)$ & $(0.0821)$ & $(0.9669)$ & $(0.1186)$ \\
Wald chi-squared & 149.1552 & 233.2539 & 171.2329 & 3.9514 & 93.5409 \\
p-value & 0.0000 & 0.0000 & 0.0000 & 0.5564 & 0.0000 \\
\hline
\end{tabular}

Note: standard deviations in parentheses.

***: significant at 1\%; **: significant at 5\%; *: significant at $10 \%$

b. Residual covariances and correlations (\%)

\begin{tabular}{cccccc}
\hline \hline Variable & Inflation & Wage & Bond & Equity & Housing \\
\hline Inflation & 0.0136 & 50.2306 & 54.9103 & 20.8439 & -15.2365 \\
Wage & 0.0047 & 0.0063 & 48.3280 & -25.8828 & -0.6701 \\
Bond & 0.0079 & 0.0047 & 0.0151 & 7.0268 & 4.7483 \\
Equity & 0.0353 & -0.0299 & 0.0125 & 2.1005 & 0.2007 \\
Housing & -0.0032 & -0.0001 & 0.0010 & 0.0005 & 0.0316 \\
\hline \multicolumn{2}{r}{ Note: correlations in italic; (co-)variances } & are in non-italic.
\end{tabular}

One-period innovations follow a multivariate normal distribution centered at 0 and with a covariance matrix given by the covariances among the residuals in the VAR $(1)$ regression (panel b. of Table 6 ). We obtain a substantially higher variance for the equity return than for the other variables. However, the standard deviation of the equity return (14.49\%) is consistent with the historical values reported in the literature (for instance, see Cocco et al., 2005) and remains of 
the same order of magnitude if we consider alternative sample periods. In contrast, if we consider alternative sample periods and use our time series to compute average historical returns, we get very different values for different sample periods. For this reason we prefer to independently set average returns following the literature.

\subsubsection{The yield curve}

We assume that the interest rates (in excess of the rate at maturity 1) that form the yield curve follow a vector autoregressive distributed lag (VADL) process of lag 1 . Our dataset is an annual time series from 1976 to 2005 of US public debt yields at maturities 2, 3, 5, 7, 10, 20 and 30. (These are the only observed maturities. Source: Federal Reserve). In our sample there are occasionally missing values for yields at maturities 20 and 30. These we impute using linear interpolation. The VADL(1) specification includes, as exogenous variables, the previous-year values of the five economic and financial variables (inflation rate, wage growth, equity, housing and bond returns).

The regression output is available upon request. In general, the excess interest rates are influenced more heavily by the previous-year realization of the excess interest rates at maturity 2 and 7 , and the returns on the bond, equity and housing markets. Shocks across the different maturities are highly positively correlated (between 71.67 and $99.51 \%$ ), while their standard deviation is higher at longer maturities $(0.6652 \%$ at $k=30$, compared to $0.1580 \%$ at $k=2)$.

The model is thus estimated at annual frequency and we use the regression output to generate random interest rates at maturities $k=2,3,5,7,10,20$ and 30 . We then adopt a linear interpolation over these yields to obtain the interest rates at any discrete maturity between 2 and 30 . Interest rates at maturity longer than 30 are set equal to the interest rate at maturity $k=30$. The average yield curve $\left\{r_{k}\right\}_{k=1}^{D}$, shown in Figure 9, exhibits a quadratically-looking pattern as a function of the maturity $k$. It increases monotonically up to $k=30$, with an estimated interest rate of $5.38 \%$.

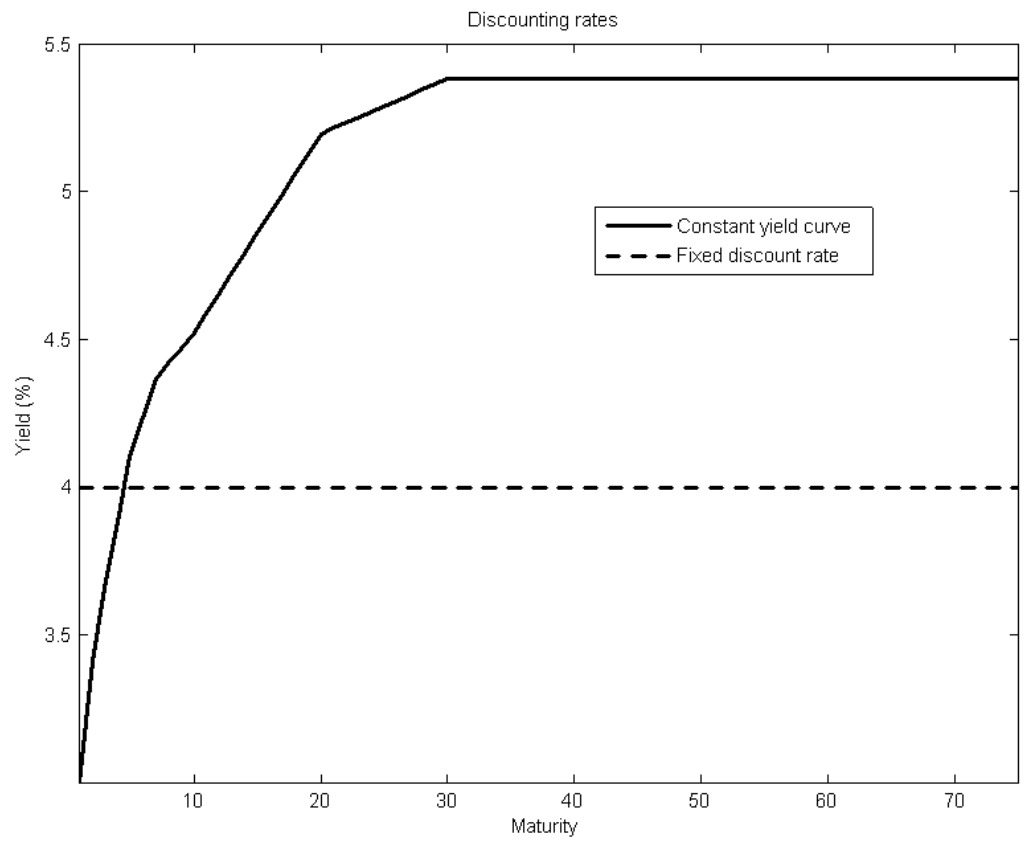

Figure 9. Average yield curve 


\subsubsection{Economic shocks based on Dutch data}

In Section 5.2 we repeat our simulation exercise using simulations of shocks based on Dutch data. We estimate a VAR equivalent to that in Appendix 7.2.3 for the US data. We use the following time series: inflation, nominal wage growth, the consumer price index and hourly wages from the OECD; for the bond and equity returns, respectively, we use the interbank 3-month yield and the MSCI Netherlands time series from Datastream. For the returns on housing, we use the NVM series on transaction sales prices (source: NVM, 2009). All our series cover the period 1986-2005. Estimation is at annual frequency. Table 7 reports the output of the VAR regression with one lag.

Table 7. $\operatorname{VAR}(1)$ regression - Dutch data

a. Deterministic coefficient estimates (matrix B in (17))

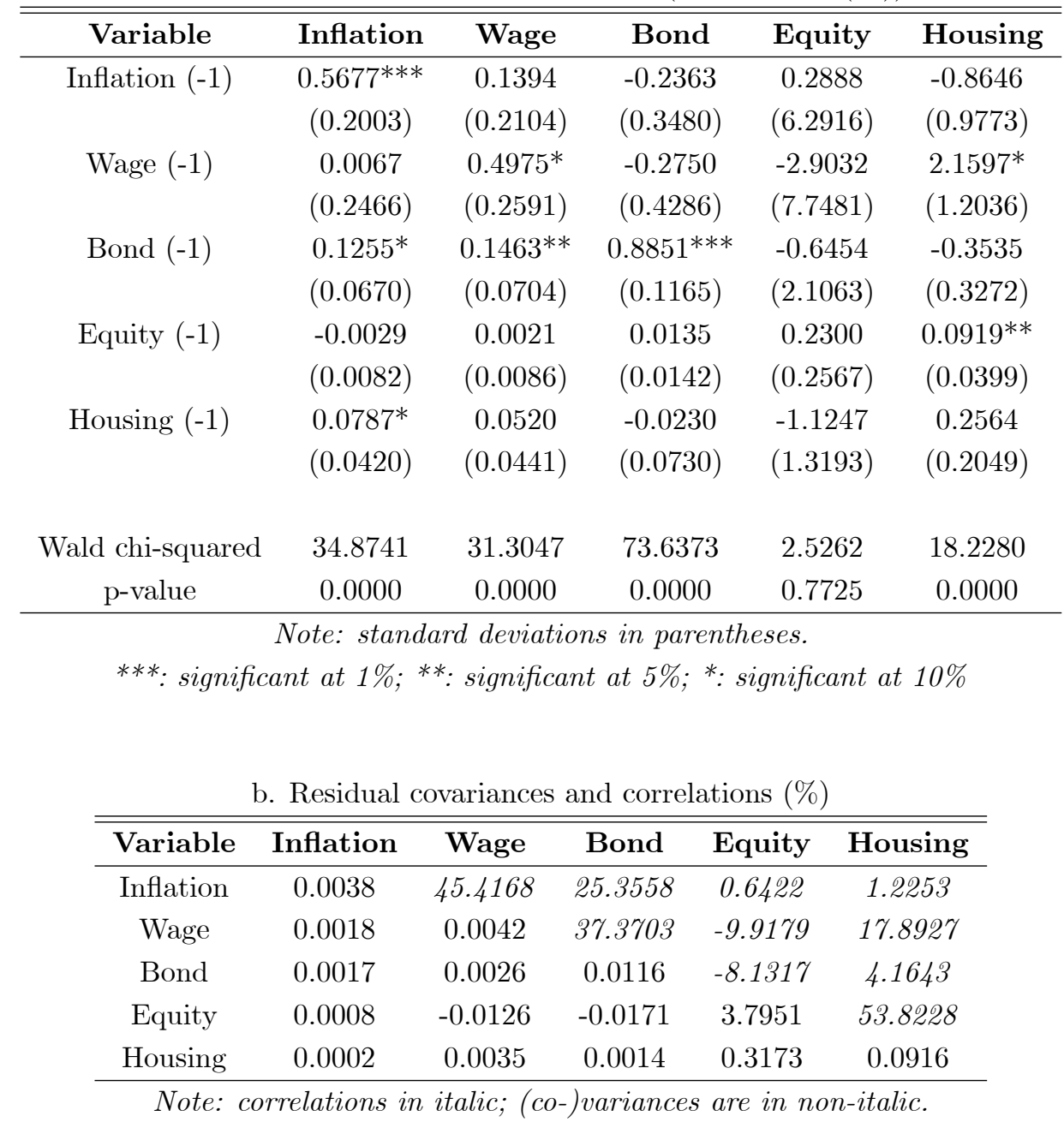

\section{References}

[1] Auerbach, A., and L.J. Kotlikoff (1987), Dynamic Fiscal Policy, Cambridge University Press, Cambridge, MA.

[2] Bonenkamp, J., and M. van de Ven (2006), "A Small Stochastic Model of a Pension Fund with Endogenous Saving", CPB Memorandum No. 168 
[3] Brennan, M.J., and Y. Xia (2002), "Dynamic Asset Allocation under Inflation", Journal of Finance, 57(3), 1201-1238.

[4] Carroll, C.D. (2006), "The Method of Endogenous Gridpoints for Solving Dynamic Stochastic Optimization Problems", Economics Letters, 91(3), 312-320.

[5] Cocco, J.F., F.J. Gomes, and P.J. Maenhout (2005), "Consumption and Portfolio Choice over the Life-Cycle", Review of Financial Studies, 18(2), 491-533.

[6] Dai, Q., and K. Singleton (2000), "Specification Analysis of Affine Term Structure Models", Journal of Finance, 55(5), 1943-1978.

[7] De Nardi, M., S. Imrohoroglu, and T.J. Sargent (1999), "Projected U.S. Demographics and Social Security", Review of Economic Dynamics, 2(3), 575-615.

[8] Datastream (2009), www.datastream.com.

[9] Diamond P.A. (2004), "Social Security", American Economic Review, 94, 1-24.

[10] DNB (2009), www.statistics.dnb.nl.

[11] Economic Policy Committee and European Commission (2006), "The Impact of Ageing on Public Expenditure: Projections for the EU25 Member States of Pensions, Health-Care, Long-Term Care, Education and Unemployment Transfers (2004-2050), European Economy, Special Reports, No.1.

[12] Evans, C., and D. Marshall (1998), "Monetary Policy and the Term Structure of Nominal Interest Rates: Evidence and Theory", Carnegie-Rochester Conference Series on Public Policy, 49(1), 53-111.

[13] Ewijk, C. van, N. Draper, H. ter Rele and E. Westerhout (2006), "Ageing and the Sustainability of Dutch Public Finances", CPB Special Publication, 61.

[14] Federal Reserve (2009), www.federalreserve.gov/releases/H15.

[15] FHFA (2009), www.fhfa.gov.

[16] Gollier, C. (2008), "inter-generational Risk-Sharing and Risk-Taking of a Pension Fund", Journal of Public Economics, 92(5-6), 1463-1485.

[17] Geanakoplos, J., and S.P. Zeldes (2008), "Reforming Social Security with Progressive Personal Accounts", NBER Working Paper, 13979.

[18] Gomes, F.J., and A. Michaelides (2005), "Optimal Life-Cycle Asset Allocation: Understanding the Empirical Evidence", Journal of Finance, 60(2), 869-904.

[19] Hansen, G.D. (1993), "The Cyclical and Secular Behaviour of the Labour Input: Comparing Efficiency Units and Hours Worked", Journal of Applied Econometrics, 8(1), 71-80.

[20] Hári, N., A. De Waegenaere, B. Melenberg, and T.E. Nijman (2007), "Longevity Risk in Portfolios of Pension Annuities", Insurance: Mathematics and Economics, 42(2), 505-519.

[21] Hubbard, R.J., and K.L. Judd (1987), "Social Security and Individual Welfare: Precautionary Saving, Liquidity Constraints, and the Payroll Tax", American Economic Review, $77(4), 630-646$. 
[22] Huggett, M., and G. Ventura (1999), "On the Distributional Effects of Social Security Reform", Review of Economic Dynamics, 2(3), 498-531.

[23] HMD (2009), www.mortality.org.

[24] Imrohoroglu, A., S. Imrohoroglu, and D.H. Joines (1995) "A Life Cycle Analysis of Social Security", Economic Theory, 6(1), 83-114.

[25] Lee, R.D., and L.R. Carter (1992), "Modeling and Forecasting U.S. Mortality", Journal of the American Statistical Association, 87(419), 659-671.

[26] NVM (2009), www.nvm.nl.

[27] OECD (2009), www.stats.oecd.org.

[28] Sánchez-Marcos, V., and A.R. Sánchez-Mártin (2006), "Can Social Security be WelfareImproving when there is Demographic Uncertainty?", Journal of Economic Dynamics $\mathcal{G}$ Control, 30(9-10), 1615-1646.

[29] Sita, N., and J.B. Shoven (2003), "Comparing the Risks of Social Security with and without Individual Accounts", American Economic Review, 93(2), 348-353.

[30] SCF (2009), wave 2007, www.federalreserve.gov/pubs/oss/oss2/scfindex.html.

[31] Tauchen, G., and R. Hussey (1991), "Quadrature-based Methods for Obtaining Approximate Solutions to Non-linear Asset Pricing Models", Econometrica, 59(2), 371-396.

[32] Teulings, C., and C. de Vries (2006), "Generational Accounting, Solidarity and Pension Losses", De Economist, 154(1), 63-83.

[33] United Nations (2009), www.un.org/esa/population.

[34] WIID (2008), version 2.0c, www.wider.unu.edu/research/Database/en_GB/database. 


\section{CESifo Working Paper Series}

for full list see www.cesifo-group.org/wp

(address: Poschingerstr. 5, 81679 Munich, Germany, office@cesifo.de)

2717 Ben J. Heijdra and Jochen O. Mierau, Annuity Market Imperfection, Retirement and Economic Growth, July 2009

2718 Kai Carstensen, Oliver Hülsewig and Timo Wollmershäuser, Price Dispersion in the Euro Area: The Case of a Symmetric Oil Price Shock, July 2009

2719 Katri Kosonen and Gaëtan Nicodème, The Role of Fiscal Instruments in Environmental Policy, July 2009

2720 Guglielmo Maria Caporale, Luca Onorante and Paolo Paesani, Inflation and Inflation Uncertainty in the Euro Area, July 2009

2721 Thushyanthan Baskaran and Lars P. Feld, Fiscal Decentralization and Economic Growth in OECD Countries: Is there a Relationship?, July 2009

2722 Nadia Fiorino and Roberto Ricciuti, Interest Groups and Government Spending in Italy, 1876-1913, July 2009

2723 Andreas Wagener, Tax Competition, Relative Performance and Policy Imitation, July 2009

2724 Hans Fehr and Fabian Kindermann, Pension Funding and Individual Accounts in Economies with Life-cyclers and Myopes, July 2009

2725 Ernesto Reuben and Arno Riedl, Enforcement of Contribution Norms in Public Good Games with Heterogeneous Populations, July 2009

2726 Kurt Schmidheiny and Marius Brülhart, On the Equivalence of Location Choice Models: Conditional Logit, Nested Logit and Poisson, July 2009

2727 Bruno S. Frey, A Multiplicity of Approaches to Institutional Analysis. Applications to the Government and the Arts, July 2009

2728 Giovanni Villani, A Strategic R\&D Investment with Flexible Development Time in Real Option Game Analysis, July 2009

2729 Luca Di Corato and Michele Moretto, Investing in Biogas: Timing, Technological Choice and the Value of Flexibility from Inputs Mix, July 2009

2730 Gilad D. Aharonovitz, Nathan Skuza and Faysal Fahs, Can Integrity Replace Institutions? Theory and Evidence, July 2009

2731 Michele Moretto and Sergio Vergalli, Managing Migration through Conflicting Policies: an Option-theory Perspective, July 2009 
2732 Volker Nitsch, Fly or Cry: Is Airport Noise Costly?, July 2009

2733 Francesco Cinnirella and Joachim Winter, Size Matters! Body Height and Labor Market Discrimination: A Cross-European Analysis, July 2009

2734 Samuel Bowles and Sandra Polanía Reyes, Economic Incentives and Social Preferences: A Preference-based Lucas Critique of Public Policy, July 2009

2735 Gary Burtless, Lessons of the Financial Crisis for the Design of National Pension Systems, July 2009

2736 Helmuth Cremer, Firouz Gahvari and Pierre Pestieau, Fertility, Human Capital Accumulation, and the Pension System, July 2009

2737 Hans Jarle Kind and Frank Stähler, Market Shares in Two-Sided Media Industries, July 2009

2738 Pamela Campa, Alessandra Casarico and Paola Profeta, Gender Culture and Gender Gap in Employment, August 2009

2739 Sebastian Gechert, Supplementary Private Health Insurance in Selected Countries: Lessons for EU Governments?, August 2009

2740 Leif Danziger, Endogenous Monopsony and the Perverse Effect of the Minimum Wage in Small Firms, August 2009

2741 Yan Dong and John Whalley, A Third Benefit of Joint Non-OPEC Carbon Taxes: Transferring OPEC Monopoly Rent, August 2009

2742 Valentina Bosetti, Carlo Carraro and Massimo Tavoni, Climate Change Mitigation Strategies in Fast-Growing Countries: The Benefits of Early Action, August 2009

2743 Christina Felfe, The Willingness to Pay for Job Amenities: Evidence from Mothers' Return to Work, August 2009

2744 Jörg Franke, Christian Kanzow, Wolfgang Leininger and Alexandra Väth, Effort Maximization in Asymmetric N-Person Contest Games, August 2009

2745 Bruno S. Frey and Paolo Pamini, Making World Heritage Truly Global: The Culture Certificate Scheme, August 2009

2746 Frank N. Caliendo, Is Social Security behind the Collapse of Personal Saving?, August 2009

2747 Caterina Liesegang and Marco Runkel, Corporate Income Taxation of Multinationals and Fiscal Equalization, August 2009

2748 Chrysovalantou Milliou and Apostolis Pavlou, Upstream Horizontal Mergers and Efficiency Gains, August 2009 
2749 Rüdiger Pethig and Christian Wittlich, Interaction of Carbon Reduction and Green Energy Promotion in a Small Fossil-Fuel Importing Economy, August 2009

2750 Kai Carstensen, Oliver Hülsewig and Timo Wollmershäuser, Monetary Policy Transmission and House Prices: European Cross-country Evidence, August 2009

2751 Olaf Posch, Explaining Output Volatility: The Case of Taxation, August 2009

2752 Beatrice Scheubel, Daniel Schunk and Joachim Winter, Don't Raise the Retirement Age! An Experiment on Opposition to Pension Reforms and East-West Differences in Germany, August 2009

2753 Daniel G. Arce, Dan Kovenock and Brian Roberson, Suicide Terrorism and the Weakest Link, August 2009

2754 Mario Larch and Wolfgang Lechthaler, Comparative Advantage and Skill-Specific Unemployment, August 2009

2755 Horst Raff and Nicolas Schmitt, Buyer Power in International Markets, August 2009

2756 Seppo Kari, Hanna Karikallio and Jukka Pirttilä, The Impact of Dividend Taxation on Dividends and Investment: New Evidence Based on a Natural Experiment, August 2009

2757 Mirco Tonin and Michael Vlassopoulos, Disentangling the Sources of Pro-social Behavior in the Workplace: A Field Experiment, August 2009

2758 Nicole Grunewald and Inmaculada Martínez-Zarzoso, Driving Factors of Carbon Dioxide Emissions and the Impact from Kyoto Protocol, August 2009

2759 Yu-Fu Chen and Michael Funke, Booms, Recessions and Financial Turmoil: A Fresh Look at Investment Decisions under Cyclical Uncertainty, August 2009

2760 Jan-Egbert Sturm and Jakob de Haan, Does Central Bank Communication really Lead to better Forecasts of Policy Decisions? New Evidence Based on a Taylor Rule Model for the ECB, August 2009

2761 Larry Karp, Sacrifice, Discounting and Climate Policy: Five Questions, August 2009

2762 Marianna Belloc and Samuel Bowles, International Trade, Factor Mobility and the Persistence of Cultural-Institutional Diversity, August 2009

2763 Charles Noussair and Fangfang Tan, Voting on Punishment Systems within a Heterogeneous Group, August 2009

2764 Birgit Bednar-Friedl and Karl Farmer, Internationally Coordinated Emission Permit Policies: An Option for Withdrawers from the Kyoto Protocol?, August 2009

2765 Pierre M. Picard and David E. Wildasin, Labor Market Pooling, Outsourcing and Labor Contracts, August 2009 
2766 Stefan Voigt and Lorenz Blume, The Economic Effects of Federalism and Decentralization - A Cross-Country Assessment, August 2009

2767 David S. Jacks, Christopher M. Meissner and Dennis Novy, Trade Booms, Trade Busts, and Trade Costs, August 2009

2768 Mario Jametti and Thomas von Ungern-Sternberg, Hurricane Insurance in Florida, August 2009

2769 Alessandro Balestrino, Kind of Black: The Musicians' Labour Market in Italy, August 2009

2770 Yosr Abid Fourati and Cathal O’Donoghue, Eliciting Individual Preferences for Pension Reform, August 2009

2771 Christian Breuer and Chang Woon Nam, VAT on Intra-Community Trade and Bilateral Micro Revenue Clearing in the EU, August 2009

2772 Choudhry Tanveer Shehzad, Jakob De Haan and Bert Scholtens, Growth and Earnings Persistence in Banking Firms: A Dynamic Panel Investigation, August 2009

2773 Erdal Yalcin, Uncertain Productivity Growth and the Choice between FDI and Export, August 2009

2774 Klaus Abberger, Wolfgang Nierhaus and Shynar Shaikh, Findings of the Signal Approach for Financial Monitoring in Kazakhstan, September 2009

2775 Sascha O. Becker, Francesco Cinnirella and Ludger Woessmann, The Trade-off between Fertility and Education: Evidence from before the Demographic Transition, September 2009

2776 Thomas Aronsson and Erkki Koskela, Optimal Income Taxation, Outsourcing and Policy Cooperation in a Dynamic Economy, September 2009

2777 Joel Slemrod, Old George Orwell Got it Backward: Some Thoughts on Behavioral Tax Economics, September 2009

2778 Cagri Seda Kumru and Athanasios C. Thanopoulos, Social Security Reform and Temptation, September 2009

2779 Alessandro Bucciol and Roel M. W. J. Beetsma, Inter- and Intra-generational Consequences of Pension Buffer Policy under Demographic, Financial and Economic Shocks, September 2009 